\title{
Why do the poor vote for low tax rates? A (real-effort task) experiment on income redistribution
}

Natalia Jimenez Jimenez, Elena Molis, and Angel Solano-Garcia

\section{ThE PAPERS}

DPTO. TEORÍA E HISTORIA ECONÓMICA WORKING PAPER SERIES 
Why do the poor vote for low tax rates? A (real-effort task) experiment on income redistribution

Natalia Jimenez Jimenez, Elena Molis, and Angel Solano-Garcia

$19 / 11$

Natalia Jimenez Jimenez, Elena Molis, and Angel Solano-Garcia (2019). Why do the poor vote for low tax rates? A (real-effort task) experiment on income redistribution. ThE Papers, Department of Economic Theory and Economic History of Universidad de Granada. 19/11. 


\title{
Why do the poor vote for low tax rates? A (real-effort task) experiment on income redistribution.
}

\author{
Natalia Jiménez Jiménez ${ }^{1}$ \\ University Pablo de Olavide and Middlesex University \\ Elena Molis \\ University of Granada \\ Angel Solano-García ${ }^{2}$ \\ University of Granada
}

October 11, 2019

\begin{abstract}
The main purpose of this paper is to shed some light on the voting behavior of low-income voters over income redistribution. To this end, we test a model based on Meltzer and Richard's (1981) framework through a lab experiment in which individuals vote over two exogenous tax rates and their pre-tax income is determined according to their performance in a real-effort task. We classify individuals into highskilled and low-skilled participants according to their performance in a tournament at the beginning of the experiment. We find that a large proportion of low-skilled workers vote for the lowest tax rate (the one that gives them the lowest payoff), especially when the alternative tax rate is very high. However, this proportion is significantly reduced in treatments in which the subjects are given extra information about how the tax operates in redistributing income. This result suggests that the lack of information about the role of taxes in income redistribution may be an important factor in explaining the counter-intuitive voting behavior of low-income voters over income redistribution. We also find that both the prospect of upward mobility and the belief in the negative effect of taxes on productivity make low-income voters support low tax rates, especially when the alternative tax rate is very high.
\end{abstract}

Keywords: income inequality, income redistribution, voting, taxation, real-effort task.

JEL: C92, D72, H30, J41.

\footnotetext{
${ }^{1}$ Natalia Jiménez Jiménez greatly acknowledges funding from Fundación BBVA for the project "El efecto del descenso de la productividad de las clases privilegiadas en el voto de las clases humildes” from Ayudas Fundación BBVA Investigadores y Creadores Culturales 2015.

2 The authors also acknowledge funding from Spanish Ministry of Economy and Competitiveness for the grant ECO201676789P.
} 
Contact information: Natalia Jiménez, Dpto. de Economía, Métodos Cuantitativos e Historia Económica, Universidad Pablo de Olavide, 41013 Sevilla, Spain. njimjim@upo.es

"If American families knew what was good for them, then most of them—all but a small, affluent minority - would cheerfully give up their tax cuts in return for a guarantee that health care would be there when needed."

Paul Krugman 2003. "Roads not taken". New York Times, April 25.

\section{Introduction}

According to the World Inequality Report (2018), income inequality has increased in almost all countries in recent decades. The speed of this increase has been different across countries, suggesting that the role of institutions and policy is important in shaping income inequality. ${ }^{3} \mathrm{~A}$ comparative example between English-speaking countries such as the US with Continental Europe or Japan seems illustrative. Top tax rates on upper-income earners have declined more sharply in English-speaking countries than in the rest of OECD countries and, as a consequence, income concentration has been more pronounced in these countries, but is much more moderate in continental Europe or Japan (Piketty, 2014; Atkinson, Piketty, and Saez, 2011 and Alvaredo et al. 2011).

Studies based on the median voter theorem, such as Romer (1975), Roberts (1977) and Meltzer and Richard (1981), state that income inequality should be self-correcting in democracies since an increased income inequality leads the median voter to demand a higher tax rate and thus, a higher level of income redistribution. Looking at the patterns of top income-tax rates and income inequality since the 1970s to today, this theory is not well supported by empirical evidence, particularly in the US (see, e.g., Roemer, 1998 and citations therein). Far from expropriating the rich, the poor seem to back less redistributive policies such as tax cuts. ${ }^{4}$ A recent illustrative example was the increased support of low-income voters in swing states such as Wisconsin,

\footnotetext{
${ }^{3}$ See Piketty and Saez (2003), Goldin and Katz (2008), Deaton (2013) and Piketty (2014) for a deeper analysis of the increase in income inequality across different countries.

${ }^{4}$ Kenworthy and McCall (2008) show how an increase in income inequality does not produce an increase in the demand for income redistribution in a variety of OECD countries.
} 
Michigan and Pennsylvania for Donald Trump (in favor of slashing taxes on the rich), which was crucial for the Republicans in winning the 2016 US presidential elections. ${ }^{5}$

The main purpose of this paper is to shed some light on the voting behavior of low-income voters over income redistribution. To this end, we test a Meltzer-Richard framework-based model through a lab experiment in which individuals vote over two exogenous tax rates and their pre-tax income is determined according to their performance in a real-effort task. This task implies the computation of several summations and was taken from Corgnet et al. (2015). Also following their design, we consider real leisure time in the workplace environment, so workers have the opportunity to browse the internet or use, for instance, social networks. We classify individuals into high-skilled and low-skilled workers according to their performance in a tournament at the beginning of the experiment. We consider two scenarios regarding the level of polarization of policy platforms: one in which polarization is moderated so the two tax rates proposed are close to each other and the other in which polarization is higher because the high tax rate is higher than in the previous scenario while the low tax rate remains the same. In contrast to the theoretical predictions, we find that a large proportion of low-skilled workers vote for the lowest tax rate, particularly when the alternative tax rate is very high.

Why would the poor vote for tax cuts? A wide range of explanations has been offered in the literature for this voting behavior. The first is related with the potential distortion of taxes on labor supply that produces the equity-efficiency trade-off presented in the models of Romer (1975), Roberts (1977) and Meltzer and Richard (1981). If the negative effect of taxes on labor supply is high enough there might be a level of the tax rate such that, above that threshold, income redistribution is decreasing in the tax rate. This is the idea behind the Laffer curve. According to this reasoning, the median voter would vote for a tax cut if they believed the tax rate to be so high that it is in the downwards sloping part of the curve, that is, if they believed that a tax cut increases tax revenue. To account for this trade-off, we incorporate this feature to both our theoretical model and our experimental design. In particular, considering true leisure time in the lab may be relevant to provide high-income workers with a weak exit option if they are disincentivized by a rise in the tax rates.

\footnotetext{
${ }^{5}$ See the press article for a detailed explanation: https://www.weeklystandard.com/john-mccormack/the-election-came-down-to77-744-votes-in-pennsylvania-wisconsin-and-michigan-updated.
} 
Another driver for low-income workers to vote for low tax rates has to do with voters' misperceptions about income redistribution and the instruments used to reduce income inequality. According to Bartels (2005), voters may fail to connect concern for income redistribution with actual public policy measures such as the tax rate. In a recent empirical study, Kuziemko et al. (2015) prove that public support for income redistribution increases if they emphasize the connection between taxation and public expenditure and the benefit of these for the poor. We address this point in our experimental design by including an additional treatment in which we better inform voters how taxation translates into public benefits for the poor.

A third group of explanations relies on the effect of voters' beliefs over their position in the income ranking or their future productivity on preferences concerning income redistribution. Gimpelson and Treisman (2018) show that the median US voter perceives she is richer than she actually is. That implies that many who would benefit from redistribution wrongly think that they would lose, so they end up demanding low levels of income redistribution. Similarly, there are some studies such as Lawrence and Sides (2014), Kuziemko et al. (2014) and Treisman (2018) that support the idea that low-income voters overstimate their income ranking ("Lake Wobegon effect”) or their productivity (“Dunning-Kruger” effect). Moreover, Benabou and Ok (2001) suggest that the prospect of upward mobility induces low-income voters to vote for low levels of income redistribution. To test this result, Agranov and Palfrey (2016) report an experimental study of a dynamic version of the Meltzer and Richard (1981) model on the effects of stochastic income mobility and tax persistence. They theoretically obtain a negative relationship between these two effects and the equilibrium tax rates. Overall, experimental results support their model. To test all these effects, we include an additional treatment in the experiment in which we ask the subjects about their relative expected performance in the task before voting for the tax rate.

Other theoretical models are based on the idiosyncratic beliefs concerning the key factors that determine economic success (Piketty 1998 and Fong 2001). Along these lines, Alesina and Angeletos (2005) propose that the equilibrium levels of public expenditure depend on voters' beliefs about how important luck versus effort (merit) is in determining their lifetime earnings. We do not test this effect since, among others (Krawczyk, 2010, Durante et al. 2014, Charité et al., 2015), it has been already done in Jimenez et al. (2019). 
We explore these theories by incorporating additional treatments. First, we consider the hypothesis that low-skilled workers do not understand the effect of taxes over income redistribution. In order to test this hypothesis, we design a new treatment (information) incorporating more accurate information about agents' payoffs after taxes for both alternative tax rates. We find that with this additional information the lower tax rate is considerably less voted for by low-income agents than in the baseline treatments in all scenarios. Therefore, these results support the hypothesis. This also suggests that the lack of information about the role of taxes in income redistribution may be an important factor in explaining the counter-intuitive voting behavior of low-income voters over income redistribution. However, still we find that a small proportion of low-income agents vote for the low tax rate.

Second, we consider the case that low-skilled workers vote for the higher tax rates because they think that doing the opposite will affect productivity. This can be explained by two different hypotheses: (1) following the idea based on the Laffer Curve, low-skilled workers may vote for the lower tax rate because the high rate could discourage high-skilled workers from working, reducing the tax revenue and therefore the redistribution; (2) low-skilled workers have a misperception of their skills and overestimate their income ranking or productivity. To test these two hypotheses, we introduce another treatment (belief) in which we aim to elicit subjects' beliefs over productivity in their group for the two tax rates proposed. We find that the Laffer curve effect can only explain why the poor vote for the low tax rate in the scenario with a very high alternative tax rate. Moreover, in line with Benabou and Ok (2001), we find that those lowskilled workers who think that they are more productive than the other low-skilled workers in their group vote more frequently for the low tax rate.

Recently, there has been extensive experimental work in economics aimed at measuring preferences for redistribution. Tyran and Sausgruber (2006) adapt the Fehr and Schmidt (1999) model into a redistribution problem. They test the predictions of the adapted inequality aversion model in a simple redistribution experiment and find that it predicts voting outcomes far better than the standard model of voting that assumes rationality and strict self-interest. Ackert et al. (2007) extend the results by Tyran and Sausgruber in a framework with different degrees of tax progressivity. In all these papers, the total amount to be distributed is exogenous, as is the initial distribution of income. By contrast, in our setting, income is endogenously determined by the effort level provided in the labor market and initial wages are determined by a tournament. 
More recent papers incorporate the efficiency-equity trade-off produced by income redistribution. For instance, Cabrales et al. (2012) propose a laboratory experiment in which rich and poor agents decide a level of costly effort (high or low) and then vote in favor of or against redistributing the generated income. They show that redistribution with high effort is not sustainable. They argue that the absence of redistribution is mainly explained because rich agents do not act differently depending on whether the poor exert a high level of effort or not. In a more recent paper, Agranov and Palfrey (2015) test in the lab the Meltzer-Richard model of equilibrium tax rates, inequality, and income redistribution. The experiment varies the amount of wage inequality and the political process used to determine tax rates. Their main findings are that the higher the inequality, the higher the tax rates. The result is robust to the political regime. They also incorporate social preferences in the Meltzer-Richard model but they have an insignificant effect on the data. As in Cabrales et al. (2012), the main difference with our setting is that we consider a real-effort task (instead of stated effort levels) to determine pre-tax income and we include leisure time. Nevertheless, Agranov and Palfrey's experimental setting is more exhaustive, since subjects could vote for any tax rate, whereas in our case we just consider two fixed tax-rate options. Finally, Sausgruber et al. (2019) analyze the differences between the disincentive effect of taxing work and redistributing tax revenues when redistribution is imposed and when it is chosen by voting. This work is the closest to ours in experimental design, since they also use a real-effort task with the option of leisure time. However, they pay for the leisure and their goals are different from ours.

The rest of the paper is organized as follows. Section 2 presents the model and the main theoretical results. The design of the experiment and the main theoretical predictions according to the model are presented in Section 3. Section 4 reports the main results and discusses the validity of the theoretical predictions. Section 5 proposes further explanations and additional treatments to test their validity. Section 6 presents the results of the additional treatments and Section 7 concludes.

\section{The Model.}

In this section, we present a model and analyze the equilibrium under the assumption of rational and self-interested agents. The economy is populated by $n>1$ agents, who participate in a perfectly competitive labor market and care about consumption and leisure. They choose an 
income tax rate through a democratic political process, which affects their labor decisions. In particular, we first study agents' decisions on labor supply with a fixed tax rate. Then, we obtain their induced preferences on the tax rate and characterize the equilibrium tax rate chosen by majority rule.

Agent $i$ is either a skilled or unskilled worker, endowed with a productivity $w_{s}$ or $w_{u}$, respectively, such that $w_{s}>w_{u}$. There are $n_{s}>0$ skilled and $n_{u}>0$ unskilled workers, with $n_{s}+n_{u}=n$ and $n_{s}<n_{u}$. Each worker, endowed with one unit of time, decides how to allocate this unit between labor $\left(x_{i}\right)$ and leisure $\left(1-x_{i}\right)$. A worker with productivity $w_{i}$ that chooses to work a fraction of $x_{i}$ of their time earns a pre-tax income of $w_{i} x_{i}$. Workers suffer a cost effort of $\frac{1}{2} x_{i}^{2}$ and enjoy a benefit from leisure of $\beta\left(1-x_{i}\right)$, with $\beta>0$ standing for the marginal benefit of leisure. ${ }^{6}$ Moreover, each worker pays a proportion of her pre-tax income $t \in[0,1]$ in taxes. We assume that tax revenues are equally distributed among all workers through a public transfer and workers' after-tax income is fully consumed. Therefore, worker $i$ 's utility function is given by the following expression: ${ }^{7}$

$$
u_{i}\left(x_{i}, t\right)=w_{i} x_{i}(1-t)-\frac{1}{2} x_{i}^{2}+\beta\left(1-x_{i}\right)+\frac{t}{n}\left(n_{s} w_{s} x_{s}+n_{u} w_{u} x_{u}\right)
$$

For a given tax rate $t$, a worker $i$ chooses to work a proportion of time $x_{i}$, such that (1) is maximized. Since the utility is strictly concave on $x_{i}$, the unique optimal labor supply for worker $i$ is:

$$
x_{i}^{*}(t)=w_{i}\left(1-t \frac{n-n_{i}}{n}\right)-\beta
$$

Intuitively, both the tax rate and the workers' valuation of leisure reduce labor supply. However, we impose that this valuation $\beta$ be low enough to have a positive optimal proportion of time devoted to work for any tax rate, i.e. $x_{i}^{*}(t)>0$. Taxes affect labor supply more intensively for skilled than for unskilled workers. This is because skilled workers are worse off after tax payments to support income redistribution towards unskilled workers. Moreover, skilled workers choose to work more time than unskilled workers if either the skill premium (ratio between

\footnotetext{
${ }^{6}$ This representation of the trade-off between labor and leisure is borrowed from Corgnet et al.(2015) and based on Holmstrom (1982).

${ }^{7}$ We use this specific utility function for the sake of simplicity. A more general utility function could be considered without changing the main results of the model. This more general analysis can be provided upon request.
} 
skilled and unskilled wages) or the proportion of skilled to unskilled workers is high enough. Skill premium has a straightforward positive incentive effect on skilled workers' labor supply. Also, the proportion of skilled to unskilled workers reduces the negative effect of income redistribution for skilled workers, increasing their willingness to work. Both the aforementioned variables reduce the possibility of social mobility. We assume that these variables are such that there is no social mobility, that is, unskilled workers are always poorer than skilled workers.

By introducing (2) into (1) we characterize workers' preferences for the tax rate, given that they choose their labor supply optimally. In Proposition 1, we state the optimal tax rates for both skilled and unskilled workers. ${ }^{8}$

Proposition 1. If the marginal benefit of leisure $\beta$ is high enough such that $x_{i}^{*} \in(0,1)$ the optimal tax rates for skilled and unskilled workers are:

$$
t_{s}^{*}=0 ; t_{u}^{*}=\frac{n\left[\left(w_{s}-w_{u}\right)\left(w_{s}+w_{u}-\beta\right)\right]}{2 n_{u} w_{s}^{2}-n_{s} w_{u}^{2}}
$$

Otherwise, $t_{s}^{*}=0$ and $t_{u}^{*}=1$.

Proof: See Appendix A.

From Proposition 1, skilled workers prefer no taxation and unskilled workers prefer a positive tax rate that allows them to enjoy certain income redistribution. For the case of skilled workers, this is because the utility function is linear in consumption and tax revenues are rebated back to all workers in equal shares. However, for unskilled workers, while a positive tax rate may benefit them with a certain income redistribution, a high enough tax rate may hurt them. This high tax rate may make both skilled and unskilled workers choose to work less time, decreasing tax revenue, which is consistent with the results related to the Laffer curve.

We next study the effect of both the workers' valuation of leisure and the skill premium in the optimal tax rate for unskilled workers. A higher valuation of leisure relative to consumption reduces the importance of income redistribution for unskilled workers and consequently reduces the intensity of preferences for a high tax rate. In addition, an increase in

\footnotetext{
${ }^{8}$ As we mentioned before, we calculate both types of workers' optimal tax rates for the case in which all workers choose to work a positive proportion of their time, that is when $\beta<w_{i}\left(1-t \frac{n-n_{i}}{n}\right)$ for all $n_{i}$. For the case in which both skilled and unskilled prefer to work their whole time (i.e. $\beta<w_{i}\left(1-t \frac{n-n_{i}}{n}\right)-1$ ) we obtain that the optimal tax rates are $t_{s}^{*}=0$ and $t_{u}^{*}=1$.
} 
the skill premium ceteris paribus makes skilled workers raise their labor supply and, therefore, the tax revenue. As a result of this, unskilled workers prefer a higher tax rate to increase income redistribution. We state these results in the following proposition.

Proposition 2. Unskilled workers' optimal tax rate decreases in the valuation of leisure time and increases in the skill premium.

\section{Proof: See Appendix A.}

In the political competition arena, since unskilled are more numerous than skilled workers, the optimal policy for unskilled workers is implemented by majority voting. This is the case when candidates are purely opportunistic in their policy proposals. To illustrate this result, let us consider a two-candidate political competition model in which the policy proposal is the tax rate. If candidates are purely opportunistic they will propose the same policy in equilibrium, which coincides with the optimal tax rate for unskilled workers. Thus, both candidates obtain a tie in elections in equilibrium. Otherwise, if a candidate proposes a different tax rate she will lose the election for sure.

Consider now a different scenario in which candidates are committed to a certain policy proposal, $\mathrm{t}^{\mathrm{h}}$ and $\mathrm{t}^{\mathrm{l}}$, one for each candidate, with $\mathrm{t}^{\mathrm{h}}>\mathrm{t}^{\mathrm{l}} \geq 0$, which are exogenously given by their ideological positions. In this case, only one candidate can win in equilibrium. The candidate who has an ideological position closer to the optimal one for the unskilled workers will win the election. More precisely, the candidate supporting a low (high) tax rate will win the election if the optimal tax rate for unskilled workers is low (high) enough. We state the previous results in the following proposition.

Proposition 3. If candidates are purely opportunistic, the tax rate chosen by majority voting is $t_{u}^{*}$. However, if policy proposals $\left\{t^{h}, t^{l}\right\}$ with $t^{h}>t^{l} \geq 0$ exogenously given, $t^{l}$ is chosen by majority voting if and only if $t_{u}^{*} \leq \frac{t^{h}+t^{l}}{2}$.

\section{Proof: See Appendix A.}

This result implies that if the proposal of the highest tax rate is very high, unskilled workers will vote for the lowest tax rate because the alternative tax rate reduces labor supply so much that it lowers their after-tax income (compensating for the redistributing effect of taxes). From Proposition 2 and 3, we can state the following corollary: 
Corollary 1. If policy proposals $\left\{t^{h}, t^{l}\right\}$ with $t^{h}>t^{l} \geq 0$ are exogenously given, $t^{l}$ is chosen by majority voting if and only if $t^{h}$ is high enough.

Proof: Straightforward from Proposition 2 and 3.

We next present an experiment to test the result stated in Corollary 1 . We first describe our experimental design and then discuss the results obtained in comparison with theoretical predictions. To explain the divergence in the results between the theory and the data we design two additional treatments including more information and subjects' beliefs about their own and others' productivity.

\section{Experimental design and theoretical predictions}

Based on the political competition model with ideological positions over the tax rate, we design an experiment in which agents with different skills have to choose between two exogenous given tax rates. We consider two treatments that vary the difference between the low and the high tax rates proposed.

Our experiment was conducted at the University of Valencia by the LINEEX experimental laboratory in 2 sessions (one per treatment) with 174 subjects, who were recruited online with software developed by LINEEX. All sessions were run in the lab, using z-Tree software (Fischbacher, 2007). No one was allowed to participate in more than one session.

One of the characteristics of the design is that subjects had to do a real-effort task in order to earn some income before voting for the preferred tax rate. This task was taken from Corgnet et al. (2015) and consisted of performing several summations. In particular, subjects had to add 16 one-digit numbers in $4 \times 4$ tables (see Figure 1). They had to add up the sum of all columns and rows in a table before writing the final solution (see the shaded cell on the lower right corner of Figure 1). They were not allowed to use a calculator or any other electronic devices. The purpose of the task was that it requires considerable mental concentration and is quite monotonous, so as to resemble a real workplace environment in which workers may browse the internet or chat with their friends through social network websites such as Facebook or Twitter. In addition, the longer the time doing the task, the harder the effort to stay focused on it. 
Figure 1. The work task

\begin{tabular}{|c|c|c|c|c|c|}
\hline & Columna1 & Columna2 & Columna 3 & Columna 4 & Suma Filas \\
\hline Flla1 & 5 & 8 & 3 & 5 & \\
\hline Fila2 & 2 & 3 & 9 & 6 & \\
\hline Fila3 & 6 & 2 & 1 & 3 & \\
\hline Fila 4 & 9 & 8 & 9 & 2 & \\
\hline Suma Columnas & $T$ & & & & \\
\hline & & & & & \\
\hline
\end{tabular}

\subsection{Treatments}

At first, we just consider two treatments which differ in the high tax rate.

Baseline treatment with a high tax rate of 0.4 (Basel_0.4, hereafter). This treatment was composed of two phases. The initial phase consisted of a tournament in which each subject performed the aforementioned real-effort task for 4 minutes. The best third of the subjects in this phase were assigned to Group A (high-skilled workers) and the rest to Group B (low-skilled workers). In the event of ties, subjects competed again in an additional round for 3 minutes. After this round, if there were additional ties, subjects were assigned randomly to Group A or B. Subjects knew that Group A members would earn more per correct table in the following stages of the session than those in Group B (see instructions in Appendix B for further details). Specifically, Group A members earned 188 ECUS per correct table, whereas those in Group B earned 75 ECUS. This stage was only played once at the beginning of the session.

In the second phase, subjects were assigned to three-person groups each formed by one person from Group A and two from Group B. These groups were fixed throughout the rest of the session. This phase lasted 9 periods, but subjects were not informed about its length. At the beginning of each period, each member of a group had to vote for one of the two tax rates proposed to them to be implemented in their group. The low tax rate was 0.2 , whereas the high rate was 0.4. In each group, the tax rate was selected by simple majority rule and it was 
announced for all group members. Subsequently, subjects had to decide how to divide the 8 minutes of the period between the real-effort task and leisure time to earn their pre-tax income. Following the design of Corgnet et al. (2015), leisure time consisted of surfing the web in the Chrome browser. This stage was the only source of real payoffs for subjects. This was common information (see instructions in Appendix B). ${ }^{9}$

Baseline treatment with a high tax rate of 0.6 (Basel_0.6, hereafter). This treatment was the same as the previous one, with the only difference being that the high tax rate proposed to subjects was 0.6 instead of 0.4 . The low tax rate stayed at 0.2 .

We summarize our treatments in the following table:'

Table 1. Initial Treatments.

\begin{tabular}{cccc}
\hline Treatment & Low tax rate & High tax rate & Subjects \\
\hline Basel_0.4 & 0.2 & 0.4 & 87 \\
Basel_0.6 & 0.2 & 0.6 & 87 \\
\hline
\end{tabular}

\subsection{Information and Payoffs}

The material payoffs in ECUS for subject $i(i=1,2,3)$ in group $j(j=A, B)$ in each period of the Voting stage was given by the function: ${ }^{10}$

$$
\pi_{i j}=(1-t) \cdot w_{j} h_{i j}+t \frac{w_{A} h_{1 A}+w_{B} h_{2 B}+w_{B} h_{3 B}}{3}
$$

\footnotetext{
${ }^{9}$ Before this phase, we included a two-period training phase in which, first, a 0.2 tax rate was announced and in the second period, the announced tax was 0.4. Agents knew that the total tax revenue collected within each group would be distributed equally between group members. After the tax rate announcement, subjects had to decide how to divide the 8 minutes of the period between the real-effort task and leisure time. This stage was irrelevant for payoffs, that is, it was hypothetical, but the idea was to help subjects to compare their payoffs for different tax rates.

${ }^{10}$ Payoffs for the Training stage were the same except that $t$ represents the exogenous tax rate implemented by the experimenter instead of that obtained through the voting procedure by the members of each group.
} 
where $t$ is the tax rate selected by simple majority within a group ( $t \in\{0.2,0.4\}$ in treatment Basel_0.4 and $t \in\{0.2,0.6\}$ in treatment Basel_0.6); $\mathrm{w}_{\mathrm{j}}$ is the payment per correct table for a subject in group $j$ (75 ECUS for subjects in Group B and 188 ECUS for subjects in Group A) and $\mathrm{h}_{\mathrm{ij}}$ is the number of correct tables solved by subject $i$ in group $j$. Note that tax revenues are equally distributed between all members of the group. We paid out one randomly selected period from among the 9 periods of the third stage. This was common information for all subjects.

In the second phase, subjects received the following information after each round: the tax rate implemented, the number of correct tables, payoffs before and after taxes for themselves and other group members.

Regarding payoffs, every ECU the subjects earned was converted to euros at an exchange rate of 1 euro $=88$ ECUS. Note that the wage rate in euros between Groups A and B was 2.5 for both treatments. On average, each person received about $25 €$ (including a $2 €$ show-up fee) for a 150 minute session.

\subsection{Theoretical Predictions}

We now incorporate the parameters' values described in our experimental design $\left(n=3, n_{s}=\right.$ $1, n_{u}=2, w_{u}=75, w_{s}=188$ ) into our theoretical model to calculate the tax rate selected by majority voting in each treatment predicted by the model. Since we don't have data about the marginal benefit of leisure $\beta$, we calculate a grid of values for this parameter consistent with the assumptions of the model. Those values are such that both skilled and unskilled prefer to work a positive amount of time and the optimal tax rate for unskilled workers is implemented in equilibrium. By (2) we find that $\beta \in$ ] $0,62.5$ [ guarantees these requirements.

By Proposition 1, we obtain the predicted optimal tax rate for both skilled and unskilled workers for the parameter of the experiment. While the optimal tax rate for skilled workers is equal to zero, the optimal tax rate for unskilled workers is between 0.5 and 0.66, as depicted in Figure 2. 
Figure 2. Optimal tax rates for unskilled workers.

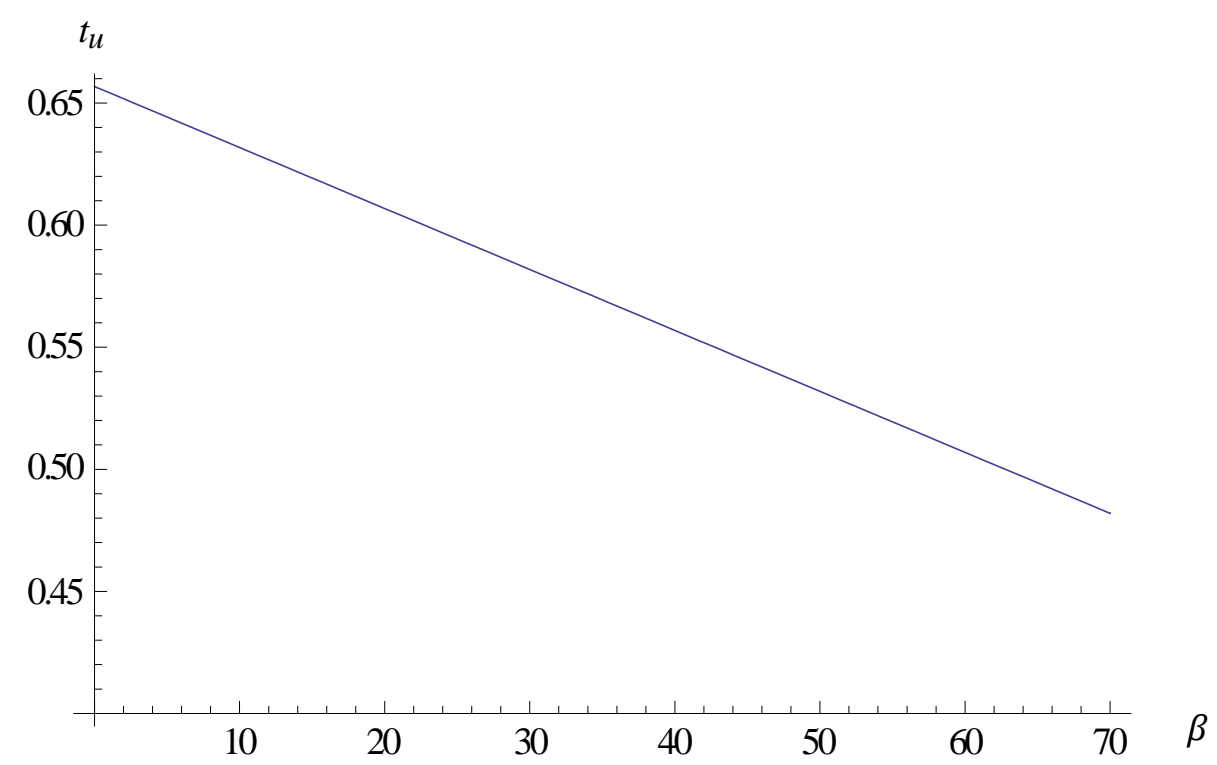

Therefore, according to Proposition 3, we find that the high tax rate (0.4 and 0.6) should be selected in both treatments since the alternative low tax rate is 0.2 , which is always at a larger distance to the optimal tax rate than the high tax rates, for any $\beta \in(0,62.5)$.

\section{Results}

In this section, we will test the theoretical predictions using the data collected from the lab experiment. To do so, we will use nonparametric statistics at an individual level to ensure independence, computing the average of all observations in the nine periods. They will reflect Mann-Whitney one-tailed tests unless stated otherwise.

Before reporting the descriptive statistics, we should check whether the differences in individual behavior between treatments might be due to differences in ability in the real task. We therefore consider the average number of correct tables provided by subjects in the two practice rounds (see the Training stage in footnote 9). ${ }^{11}$ We find that the difference between skill distributions for both high tax rates is not statistically significant ( $p=0.210$, two-tailed test).

\footnotetext{
${ }^{11}$ The reason we select the practice rounds and not the first round (without tax-rate scheme) is that the pressure of being assigned to the high-wage group depending on the outcome of this round may bias the real skill distribution of subjects.
} 
Once we have checked that the skill distribution is similar between treatments, we can analyze individual behavior in a more transparent way. Table 2 reports some descriptive statistics about subjects' decisions on voting. From now on, we will label high-skilled workers as "Rich" and low-skilled workers as "Poor”.

Table 2: Descriptive statistics of agents' decisions on voting.

\begin{tabular}{|c|c|c|c|c|c|c|}
\cline { 2 - 7 } \multicolumn{1}{c|}{} & \multicolumn{4}{c|}{ High Tax Rate $=0.4$} & \multicolumn{3}{c|}{ High Tax Rate = 0.6 } \\
\hline Agents & All & Rich & Poor & All & Rich & Poor \\
\hline $\begin{array}{l}\text { \% votes for the low } \\
\text { tax (0.2) }\end{array}$ & 52 & 84 & 36 & 65 & 83 & 56 \\
\hline $\begin{array}{l}\text { \% high tax (0.4/0.6) } \\
\text { implemented }\end{array}$ & \multicolumn{3}{|c|}{52} & & & 28 \\
\hline N & 87 & 29 & 58 & 87 & 29 & 58 \\
\hline
\end{tabular}

Note: Rich[Poor] refers to those subjects receiving the high[low] wage.

As expected, high-skilled (Rich) agents vote mostly for the low tax rate in both treatments. Surprisingly, low-skilled (Poor) workers vote much more frequently for the low tax rate (36\% and $56 \%$ for 0.4 and 0.6 high tax rate, respectively) than predicted ( $0 \%$ for both), especially when the high tax rate is severe (high tax rate equals to 0.6). ${ }^{12}$ Moreover, low-skilled workers vote significantly more for the low tax rate when the high tax rate is severe $(p=0.002)$. This is in line with Corollary 1 , that is, a high polarization of policy proposals increases the chance that the low-skilled workers vote for the low tax rate. Unfortunately, this result is not predicted by the model with the parameter values of the experiment.

Another variable we may explore is the percentage of low-skilled workers who vote mostly (more than 4 periods out of 9) according to the model, that is, they vote for the high tax rate. This amounts to $66 \%$ and $40 \%$ for the 0.4 and 0.6 high tax rate, respectively. Not surprisingly, these percentages decrease to $36 \%$ and $12 \%$, respectively, when we consider the percentage of low-skilled workers who vote for the high tax rate in all nine periods. Again, those results deviate considerably from the theoretial predictions.

\footnotetext{
12 Note that the theoretical predictions are based on the assumption that the leisure time has a sufficient low value for agents. This is supported by our experimental results since average time spent on web surfing by rich from a total of 480 seconds was 4.7 and 2.3 for the 0.4 and 0.6 high tax rate, respectively; and for the poor it was 3.7 and 3.3 for the 0.4 and 0.6 high tax rate, respectively.
} 
Regarding the implemented tax rate, the hypothesis of the median voter theorem states that the high tax rate should always be the winner in both treatments. Nevertheless, this only happens $52 \%$ and $28 \%$ of the time in the 0.4 and 0.6 treatments, respectively. These results contrast sharply with those in Agranov and Palfrey (2015). They found that the implemented tax rate in their two treatments was not significantly different from the median of the votes in each group. This contrast may be due to the differences in the experimental design. They consider groups of 5 people while we consider 3. They have a continous tax rate to vote for, while we have just two exogenous tax rates. Finally, we consider a real task and leisure time in the workplace, while their task is stated with no feasible leisure.

The introduction of the real task in our design may involve some issues that may explain the previous results. It could be the case that there are some "very productive" low-skilled workers who will earn more by voting for the low tax rate, that is, given other group members' productivity, their earnings post-tax redistribution will be higher for the low tax rate than for the high one. However, this only happens in 8\% and 4\% of the cases in Basel_0.4 and Basel_0.6, respectively. ${ }^{13}$ Thus, this does not seem to be a relevant explanation.

In order to explore other potential explanations for these puzzling results, we state some hypotheses in the next section.

\section{Hypotheses and Additional Treatments}

Our first hypothesis is based on the possible misperception of the role of taxes on income redistribution and so of their benefits towards the poor. Low-skilled workers may not be aware that a high tax rate benefits them more than a low tax rate since they do not connect taxation with redistribution of income from the skilled to the low-skilled workers (Bartels, 2005 and Kuziemko et al., 2015).

Hypothesis 1: Low-skilled workers vote for the low tax rate because they do not properly understand how the tax rate is related with income redistribution.

To test this hypothesis, we propose the following treatment:

\footnotetext{
${ }^{13}$ Moreover, in those cases low-skilled workers voted for the low tax rate only $77 \%$ and $66 \%$ of the time, for Basel_0.4 and Basel_0.6, respectively.
} 
Information Treatment (Info). This is the same as the baseline but we also provide own and other group members' payoffs after tax redistribution with the complementary (nonimplemented) tax rate in the feedback after each round, assuming that productivity will remain constant within groups (we explicitly inform subjects about this assumption on the screen).

Our second hypothesis is based on taxes' disincentive for productivity. If low-skilled workers believe that high-skilled workers will be disincentivized when the implemented tax rate increases, even to the point that low-skilled payoffs after redistribution will also decrease (Laffer curve effect), then this may explain why low-skilled workers vote more than expected for the low tax rate. Note that here the relevant result is whether low-skilled workers believe that this happens and not whether this actually happens.

Hypothesis 2: Low-skilled workers who believe that high-skilled workers will work less with a higher tax rate, vote more frequently for the low tax rate.

To test this hypothesis, we need to elicit subjects' beliefs on productivity. There are two possible ways to analyze this: within and between subjects. The former will be obtained by the comparison of subjects' beliefs between the two tax rates within each treatment, that is, the low vs the high tax rate. For the latter, we will compare beliefs between the two high tax rates ( 0.4 vs 0.6) between treatments.

Finally, our last hypothesis concerns the evidence in the literature of two phenomena. First, lowskilled workers may overestimate their income ranking ("Lake Wobegon effect”) or their productivity ("Dunning-Kruger” effect). Indeed, some empirical studies demonstrate these effects (Lawrence and Sides 2014, Kuziemko et al. 2014 and Treisman 2018). Another possibility is related to the prospect of upward mobility (Benabou and Ok 2001), by which lowskilled workers will believe that in the future they will be closer to the high-skilled than to the low-skilled in their group. In any of these cases, low-skilled workers may have incentives to vote for the low tax rate.

Hypothesis 3: Those low-skilled workers who believe that they are much more productive than the other low-skilled workers, vote more frequently for the low tax rate. 
To test the previous two hypotheses, we propose the following treatment:

Belief Treatment (Belief). This is the same as the baseline but we elicit subjects' beliefs over their own and other group members' number of correct tables under both exogenous tax rates. This elicitation is made before they vote for the tax rate. With these beliefs, we compute their payoffs after redistribution for each tax rate scheme and we show them to subjects on the screen. They earn $5 €$ if those payoffs were correct in a randomly chosen round.

Notice that in the Belief treatment, subjects may infer some information on the functionality of the tax rate as an instrument of income redistribution, which helps them to think about the effect of taxes on their payoffs. Nevertheless, in this treatment our focus will be on the effect of the beliefs and not on the comparison of actual voting decisions with the baseline treatments, whereas in the Info treatment we are mainly interested in the effect of the information on the voting decisions.

We summarize our treatments in Table 3:

Table 3. Initial and Additional Treatments

\begin{tabular}{|c|c|c|c|c|}
\hline Treatments & Additional feature & Low tax rate & High tax rate & Subjects \\
\hline Basel_0.4 & - & 0.2 & 0.4 & 87 \\
\hline Basel_0.6 & - & 0.2 & 0.6 & 87 \\
\hline Info_0.4 & $\begin{array}{c}\text { Extra information } \\
\text { on the role of } \\
\text { taxation }\end{array}$ & 0.2 & 0.4 & 30 \\
\hline Info_0.6 & $\begin{array}{c}\text { Extra information } \\
\text { on the role of } \\
\text { taxation }\end{array}$ & 0.2 & 0.6 & 30 \\
\hline Belief_0.4 & $\begin{array}{l}\text { Elicitation of } \\
\text { beliefs on } \\
\text { productivity }\end{array}$ & 0.2 & 0.4 & 30 \\
\hline Belief_0.6 & $\begin{array}{l}\text { Elicitation of } \\
\text { beliefs on } \\
\text { productivity }\end{array}$ & 0.2 & 0.6 & 30 \\
\hline
\end{tabular}




\section{Additional Results}

In this section, we test our hypotheses using the data collected from the lab experiment. To do so, we first study the voted and implemented tax rates, then we analyze the performance in the task, and, lastly, we focus on efficiency and inequality. To test the validity of our hypotheses, we use both nonparametric statistics and econometric analysis. For the latter analysis, we will use both Random Effects Logit to check the robustness of our statistical results.

Again, before analyzing the differences in individual behavior, we should check the differences in the skill distribution. ${ }^{14}$ Figures $3 a$ ) and 3b) plot the corresponding histograms for the distribution of this variable within each treatment for both scenarios regarding the level of polarization of the tax rates proposed. The visual result of no important differences between skill distributions for both high tax rates is statistically confirmed (minimum $p=0.212, p=0.286$, for 0.4 and 0.6 high tax rates, respectively; two-tailed tests, pair-wise comparisons) except for Basel_0.4 and Belief_0.4 where the differences are weakly significant ( $p=0.168$, two-tailed). ${ }^{15}$ To account for this, in our econometric analysis we will control for skill in the task.

Figure 3 a) Skill distribution in the treatments with high tax rate $=\mathbf{0 . 4}$.

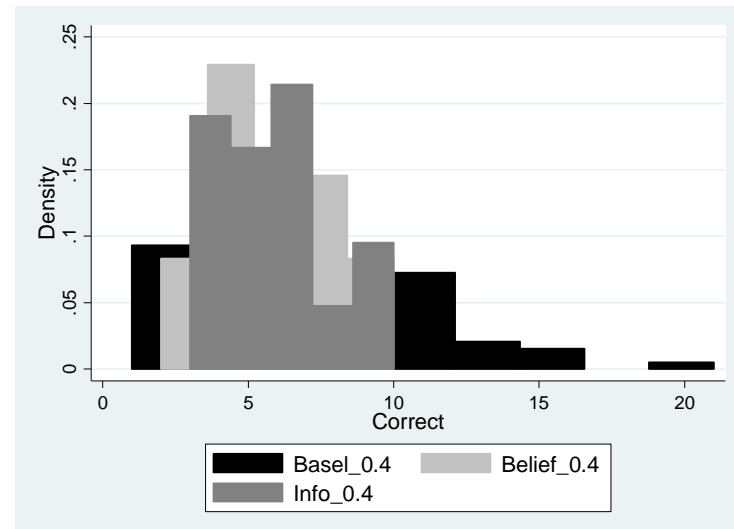

Figure 3 b) Skill distribution in the treatments with high tax rate $=\mathbf{0 . 6}$.

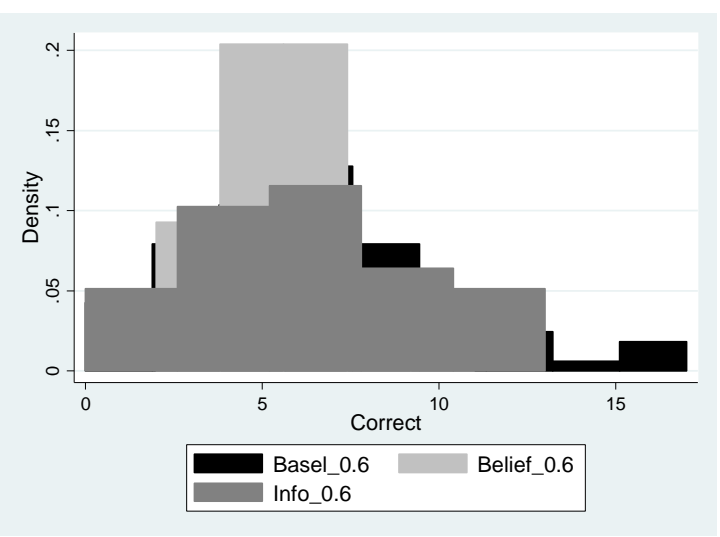

\footnotetext{
${ }^{14}$ As before, we consider the average number of correct tables provided by subjects in the two practice rounds (see the Training stage in the experimental design section).

${ }^{15}$ We have also performed a Kruskal-Wallis equality-of-populations rank test for 3 independent samples and the differences are not significant ( $\mathrm{p}=0.212, \mathrm{p}=0.286$, for 0.4 and 0.6 high tax rates, respectively; two-tailed tests).
} 
Once we have checked that the skill distribution is similar between treatments, we can analyze individual behavior in a more transparent way. ${ }^{16}$ Table 3 reports some descriptive statistics about agents' decisions in the experiment.

Table: Descriptive statistics of agents' decisions

\begin{tabular}{|c|c|c|c|c|c|c|c|}
\hline & & \multicolumn{3}{|c|}{ High Tax Rate $=0.4$} & \multicolumn{3}{|c|}{ High Tax Rate $=0.6$} \\
\hline \multicolumn{2}{|c|}{ Agents } & All & Rich & Poor & All & Rich & Poor \\
\hline \multirow{3}{*}{$\begin{array}{l}\% \text { votes for } \\
\operatorname{tax}=0.2\end{array}$} & Basel & 52 & 84 & 36 & 65 & 83 & 56 \\
\hline & Belief & 48 & 88 & 28 & 52 & 83 & 36 \\
\hline & Info & 39 & 90 & 13 & 49 & 94 & 26 \\
\hline \multirow{3}{*}{$\begin{array}{l}\% \text { tax }=0.2 \\
\text { implemented }\end{array}$} & Basel & \multicolumn{3}{|c|}{48} & \multicolumn{3}{|c|}{72} \\
\hline & Belief & \multicolumn{3}{|c|}{46} & \multicolumn{3}{|c|}{50} \\
\hline & Info & \multicolumn{3}{|c|}{22} & \multicolumn{3}{|c|}{40} \\
\hline \multicolumn{2}{|l|}{$\mathrm{N}$} & 144 & 48 & 96 & 144 & 48 & 96 \\
\hline
\end{tabular}

Note: Rich[Poor] refers to those subjects receiving the high[low] wage.

\subsection{Information.}

Our focus here is the comparison between decisions in the Baseline and in the Info treatments to test Hypothesis 1 . Our first result is that the implementation of the high tax rate is more likely in the Info treatment than in the Baseline and it is highly significant. ${ }^{17}$ This result is clearly driven by Poor voting behavior since Rich agents voted very similarly in all treatments. ${ }^{18}$ The Poor vote significantly more frequently for the low tax rate in the Baseline than in the Info treatments for

\footnotetext{
${ }^{16}$ Again, we can compute those cases where Poor earnings after tax redistribution are higher for the high tax rate than for the low one. This only happened in $8 \%, 5 \%, 2 \%, 3 \%, 8 \%$ and $8 \%$ of the cases in Basel_0.4, Basel_0.6, Info_0.4, Info_0.6, Belief_0.4 and Belief_0.6, respectively.

${ }^{17}$ This result also holds for the comparison between Info and Belief although it is not significant. For the 0.4 high tax rate, $p=$ $0.008, p=0.373$, for Basel vs Info, for Belief vs Info, respectively. For the 0.6 high tax rate, $p=0.042, p=0.470$, for Basel vs Info, for Belief vs Info, respectively.

${ }^{18}$ For the 0.4 high tax rate, $p=0.646, p=0.717, p=0.755$, for Basel vs Info, for Basel vs Belief and for Belief vs Info, respectively. For the 0.6 high tax rate, $p=0.551, p=0.825, p=0.298$, for Basel vs Info, for Basel vs Belief, for Belief vs Info, respectively. All these tests are two-tail.
} 
both high tax rates, the 0.4 (36\% vs $13 \%$ ) and the 0.6 (56\% vs $26 \%) .{ }^{19}$ Therefore, Hypothesis 1 is highly supported.

To check the robustness of previous results, we develop an econometric analysis. Here, we can take advantage of the panel data set structure (time, agents) and we do not lose individual information as we did with the tests. We consider a Random Effects (RE) Logit model where the dependent variable is the probability that the low tax rate is voted for in the next period. As explanatory variables, we use a dummy for Rich agents (Rich), the total amount of tax collected within each group in the present period (Tax collect), the number of correct tables in the present period (Correct), the amount of web-surfing time in the present period (Surf), the dummy, which is 1 if the implemented tax rate was the low rate after the voting procedure in the present period (Winner low tax), the current period (Period), the group identification number (Group) and the dummy treatment for the Baseline (Baseline). ${ }^{20}$ As our focus is on the behavior of the Poor, we report two specifications, one including all the observations of the Baseline and Info treatments (All) and another including only the Poor subsample (Poor).

Table 5. Probability of voting the low tax rate in the next period

\begin{tabular}{l||cc||cc}
\multicolumn{2}{c}{} & \multicolumn{2}{c}{\begin{tabular}{c} 
BASELINE VS INFO \\
\multicolumn{1}{c}{ (High tax rate $=\mathbf{0 . 4})$}
\end{tabular}} & \multicolumn{2}{c}{$\begin{array}{c}\text { BASELINE VS INFO } \\
\text { (High tax rate }=\mathbf{0 . 6})\end{array}$} \\
\hline Variables & $(1)$ & $(2)$ & $(1)$ & $(2)$ \\
& All & Poor & All & Poor \\
\hline \multirow{4}{*}{ Rich } & & & & \\
& $5.043^{* * *}$ & - & $3.960^{* * *}$ & - \\
Tax collect & $(0.746)$ & & $(0.756)$ & \\
& $-0.004^{*}$ & $-0.005^{* *}$ & -0.001 & -0.002 \\
Correct & $(0.002)$ & $(0.002)$ & $(0.002)$ & $(0.002)$ \\
\multirow{5}{*}{ Surf } & $0.121^{*}$ & 0.0893 & 0.045 & -0.008 \\
& $(0.065)$ & $(0.078)$ & $(0.070)$ & $(0.073)$ \\
Winner low & -0.002 & -0.019 & $0.012^{* *}$ & 0.007 \\
tax & $(0.005)$ & $(0.024)$ & $(0.00)$ & $(0.005)$ \\
Group & $0.313^{*}$ & $0.778^{*}$ & -0.061 & -0.227 \\
& $(0.171)$ & $(0.431)$ & $(0.728)$ & $(0.789)$ \\
& -0.098 & -0.038 & -0.038 & 0.032 \\
& $(0.071)$ & $(0.074)$ & $(0.071)$ & $(0.071)$
\end{tabular}

\footnotetext{
${ }^{19} p=0.013$ and $p<0.001$, for Basel vs Info, for the 0.4 and 0.6 high tax rates, respectively.

${ }^{20}$ We include the explanatory variables Tax collect and Group in order to control in some way for the effect of all the periods being with the same partners in the group.
} 


\begin{tabular}{l||cc||cc} 
Period & 0.0004 & 0.0353 & 0.004 & -0.005 \\
& $(0.052)$ & $(0.068)$ & $(0.057)$ & $(0.064)$ \\
Baseline & $0.441^{* *}$ & $0.649^{* * *}$ & $0.487^{* * *}$ & $0.650^{* * *}$ \\
& $(0.184)$ & $(0.192)$ & $(0.171)$ & $(0.204)$ \\
Constant & -0.534 & 0.063 & $9.628^{* * *}$ & $2.444^{*}$ \\
& $(0.900)$ & $(1.287)$ & $(2.001)$ & $(1.312)$ \\
& & & & \\
$\mathrm{N}$ & 928 & 624 & 928 & 624 \\
\hline
\end{tabular}

Once more, we find that the low tax rate is less frequently voted for in the Info than in the Baseline treatment (Baseline dummy positive and highly significant). Again, this result supports Hypothesis 1 (confirming our previous statistical findings). We also find a negative effect of the amount collected by the tax in the likelihood of voting for the low tax rate, which is quite intuitive if agents believe that they will increase their earnings by voting for the high tax rate. Nevertheless, this effect is only significant under the 0.4 high tax rate. Finally, we find an effect on the voting trend within groups only when the high tax rate is 0.4 , that is, the probability of voting for the low tax rate in the next period is higher if the implemented tax rate in the current period is the low one.

Even though we do not report the coefficients for the Rich subsample, we have computed them for the same specifications as those in Table 5 and the only variable that is significant (and positive) is the surf time. That is, those Rich who used the surf time more frequently are more likely to vote for the low tax rate in the next period. Thus, it seems that even if on average the use of leisure in the workplace is very reduced, it has an effect on the voting behavior, although only significant for the Rich. Note that this is really a lower bound of the real effect of leisure in the workplace because in real life workers do not clearly lose a big part of their salaries when not being productive. ${ }^{21}$ All in all, we can state the following result:

Result 1. Low-skilled agents vote more frequently for the high tax rate when they receive information on how the tax rate is related to the income redistribution.

\footnotetext{
${ }^{21}$ For more details about leisure time decisions see Appendix C.
} 


\subsection{Beliefs about performance in the task}

To test our second and third hypotheses, we analyze the beliefs over individuals' productivity elicited in the Belief treatments.

First, we will explore whether the poor who believe that the rich will work less with a higher tax rate will vote more frequently for the low tax rate. The within-treatment comparison seems a very straightforward and intuitive way, since we will compare the voting decisions of the same individuals under the two tax regimes. In Belief_0.4 the increase from the low to the high tax rate is quite moderate (20\%), so we may expect a moderate effect. Those Poor who believe that the Rich's productivity decreases under the high tax rate $(0.4)$ vote for the low tax rate $57 \%$ of the time, while the Poor who belief that the Rich's productivity will increase vote (for the low tax rate) just $40 \%$ of the time. ${ }^{22}$ When the high tax rate is 0.6 , the increase from the low to the high tax rate is now $40 \%$, so we expect a higher impact of beliefs on the voting behavior. Those Poor who believe that the Rich's productivity decreases under the high tax rate (0.6) vote for the low tax rate $45 \%$ of the time, while the Poor who believe the opposite vote for it just $18 \%$ of the time. Only for the 0.6 high tax rate are those differences weakly significant, so Hypothesis 2 is mainly supported when the tax schemes proposed are polarized. ${ }^{23}$

Next, and as a robustness check, we perform the between-treatments comparison. As before, we need to verify that the skill distribution is not statistically different between treatments. ${ }^{24}$ Here, we will compare voting behavior under the high tax rate in the two Belief treatments, so the increase between tax rates is now 20\%. Thus, this may in some way be compared with the results found in the within-subjects analysis of the Belief_0.4 treatment. First, we need to check whether the Poor actually think that the Rich will decrease their productivity when increasing the high tax rate from 0.4 to 0.6. The Poor's beliefs about the Rich's number of correct tables was 8.70 and 6.83 for 0.4 and 0.6 high tax rates, respectively. ${ }^{25,}{ }^{26}$ As reported in Table 4, the Poor voted for the low tax rate 28\% and 36\% in Belief_0.4 and Belief_0.6,

\footnotetext{
${ }^{22}$ In the Belief_0.4 treatment, we have eliminated an outlier observation (beliefs about Rich’s productivity under 0.2) of 999.

${ }^{23} p=0.969$, two-tailed and $p=0.087$ for Belief_0.4 and Belief_0.6, respectively.

${ }^{24} p=0.481$ for the comparison of the correct number of tables between Belief_0.4 and Belief_0.6, two-tailed test.

${ }^{25}$ Interestingly, although the difference in beliefs is significant $(p=0.044)$, the Rich's actual productivity was not statistically different between those treatments (8.88 vs 7.56, for Belief_0.4 vs Belief_0.6, $p=0.684$, two-tailed).

${ }^{26}$ In the Belief_0.4 treatment, we have eliminated an outlier observation (beliefs about Rich’s productivity under 0.4) of 100.
} 
respectively. Although quantitatively this result supports Hypothesis 2, the differences are not statistically significant. ${ }^{27}$ Hence, this is in line with what we found previously for Belief_0.4.

A possible caveat in the previous statistical comparisons is that the number of cases in which the Poor believe that the Rich decrease their productivity is reduced. Thus, we should go one step further in the analysis and conduct some regressions in order to check whether our data support Hypothesis 2.

In Table 6, we consider two different regressions to test Hypothesis 2, that is, whether the Poor vote more frequently for the low tax rate when they believe that the Rich will decrease their productivity for a higher tax rate. The first (1) accounts for the within-subjects analysis. Thus, we consider a RE Logit on the probability of voting for the low tax rate. We include an additional variable: Beliefs for rich disincentive, a dummy that is 1 if the Poor's beliefs about the Rich's number of correct tables under the high tax rate are smaller than under the low one. We interact the last dummy with each treatment dummy to see whether there is a significant effect of these beliefs on the voting behavior in each treatment independently. We aim to study the betweensubjects effect with the second specification (2) of the previous model. Now, we do not consider the former interaction of the dummies but the treatment dummy Belief_0.6. Therefore, we can check whether subjects vote more frequently for the low tax rate in Belief_0.6 than in Belief_0.4. For both regressions, we only consider those observations from Poor agents' voting decisions of the two Belief treatments (Belief_0.4 and Belief_0.6). ${ }^{28}$ We also include the variable Skill to account for differences in the skill distribution between treatments.

Table 6. Effect of Poor beliefs about rich productivity for higher tax rates on the probability of voting for the low tax rate.

\begin{tabular}{l||c|c}
\hline Variables & $\begin{array}{c}\text { (1) } \\
\text { Probability of voting for } \\
\text { the low tax rate }\end{array}$ & $\begin{array}{c}\text { Probability of voting for } \\
\text { the low tax rate }\end{array}$ \\
\hline Beliefs for rich disincentive & - & $\begin{array}{l}1.190^{*} \\
(0.649)\end{array}$ \\
Beliefs for rich & 0.702 & \\
disincentive* Belief_0.4 & $(0.830)$ & \\
Beliefs for rich & $1.870^{*}$ &
\end{tabular}

\footnotetext{
${ }^{27} p=0.358$, two-tailed.

${ }^{28}$ We have eliminated 29 observations from those subjects who provide beliefs about Rich productivity of 0,50 or 99 correct tables (the average number of correct tables by the Rich was 10).
} 


\begin{tabular}{l||c|c} 
disincentive* Belief_0.6 & $(1.036)$ & $-0.009 * * *$ \\
Tax collection in t-1 & $-0.009 * * *$ & $(0.002)$ \\
& $(0.002)$ & $0.199 * * *$ \\
Period & $0.194^{* *}$ & $(0.088)$ \\
& $(0.088)$ & 0.027 \\
Skill & 0.032 & $(0.227)$ \\
& $(0.235)$ & 1.075 \\
Belief_0.6 & - & $(0.882)$ \\
Constant & -0.219 & -0.616 \\
& $(1.485)$ & $(0.947)$ \\
& & 320 \\
Observations & 320 \\
\hline Note: Beliefs for rich disincentive is a dummy that is 1 if the Poor's beliefs about the Rich’s \\
number of correct tables under the low tax rate are higher than under the high rate.
\end{tabular}

In regression (1), we observe that the interaction between Beliefs for rich disincentive and the dummy treatment for Belief_0.4 is not significant, while it is weakly significant (and positive) for Basel_0.6. This is exactly the same result we found with the tests. Thus, we find no support for Hypothesis 2 when the tax rate increases from 0.2 to 0.4 and a weak support when it increases from 0.2 to 0.6. Similarly, we find no significant effect when increasing the high tax rate from 0.4 to 0.6 (dummy Belief_0.6 in regression (2)) when we control for the effect of the Poor's beliefs about tax disincentive on the Rich's productivity. It is not surprising that as the difference between tax rates increases, beliefs about disincentive on the Rich's productivity have a higher effect on the low tax votes by the Poor. ${ }^{29}$

Result 2. Those low-skilled workers who believe that the high-wage workers will significantly decrease their productivity if a high tax rate is chosen are more likely to vote for the low tax rate only when the alternative tax rate is high enough.

The other possible explanation was related with the overestimation of own productivity by the Poor. We will consider two different measures. First, we check whether the Poor's beliefs about the (positive) difference between their own correct tables and those of the other poor in the

\footnotetext{
${ }^{29}$ In fact, on average the Poor believe that the Rich will make 2.6 more correct tables in Belief_0.4 than in Belief_0.6.
} 
same group is higher when they voted for the low tax rate than when they vote for the high one. This is the case in both treatments: 6.33 vs 2.94 and 3.43 vs 2.11, for Belief_0.4 and Belief_0.6, respectively. However, these differences are not statistically significant. A possible issue with this variable is that the total number of cases where the Poor voted for the low tax rate are quite few. A different measure which diminishes this issue is the correlation coefficient between the frequency of votes for the low tax rate and the (positive) difference between own correct tables and those of the other poor in the same group. The correlations amount to $40 \%$ and $38 \%$, for Belief_0.4 and Belief_0.6, respectively. And now, the coefficients are highly significant ( $<<0.001$ both). Again, we need an additional econometric analysis to provide a better conclusion regarding Hypothesis 3.

Table 7 reports the effect of the Poor's beliefs about the other Poor's productivity on their voting behavior. We include two additional explanatory variables: Belief difference for the low [high tax rate]. These are the difference between the poor's beliefs about their own number of correct tables minus the poor's beliefs about the number of correct tables of the other poor in the same group, if both beliefs are under the low [high tax] rate and only if the difference is strictly positive. In this way, we can analyze whether the Poor change their vote more frequently for the high tax rate when they believe that they are more productive than the other poor in their group. To this end, we interact the previous variables with the treatment dummies for Basel_0.4 and Basel_0.6. We consider two different specifications of the RE logit model since beliefs about productivity under the low tax rate are highly correlated with those beliefs under the high tax rate.

Table 7. Voting behavior and poor beliefs about other poor productivity.

\begin{tabular}{l||cc}
\hline Variables & $\begin{array}{c}(1) \\
\text { Probability of } \\
\text { voting for the } \\
\text { low tax rate }\end{array}$ & $\begin{array}{c}(2) \\
\text { Probability of } \\
\text { voting for the low } \\
\text { tax rate }\end{array}$ \\
\hline $\begin{array}{l}\text { Belief difference for the } \\
\text { Low tax rate* Belief_0.4 }\end{array}$ & $\begin{array}{c}0.285 \\
(0.336)\end{array}$ & \\
Belief difference for the & $\begin{array}{c}0.998^{* *} \\
(0.465)\end{array}$ & \\
Low tax rate* Belief_0.6 & & $0.495^{*}$ \\
Belief difference for the & & $(0.297)$ \\
High tax rate* Belief_0.4 & & $1.273^{* *}$ \\
Belief difference for the & &
\end{tabular}




\begin{tabular}{l||cc} 
High tax rate* Belief_0.6 & & $(0.505)$ \\
Tax collection in t-1 & $-0.020^{* * *}$ & $-0.013^{* * *}$ \\
& $(0.007)$ & $(0.004)$ \\
Correct in t-1 & -0.099 & -0.298 \\
& $(0.322)$ & $(0.269)$ \\
Skill & 0.132 & 0.152 \\
& $(0.319)$ & $(0.308)$ \\
Group & 0.169 & 0.066 \\
& $(0.243)$ & $(0.202)$ \\
Period & 0.262 & 0.213 \\
& $(0.226)$ & $(0.184)$ \\
Constant & -1.408 & -1.033 \\
& $(2.569)$ & $(2.295)$ \\
\multicolumn{1}{l}{ Observations } & & \\
\hline
\end{tabular}

Note: Belief difference for the low [high] tax rate is the difference between the poor's beliefs about their own number of correct tables minus the poor's beliefs about the number of correct tables of the other poor in the same group, if both beliefs are under the low [high] tax rate and only if the difference is strictly positive.

As expected, if poor agents believe that they are more productive than the other poor in their group, it is more likely that they vote for the low tax rate. This effect is only significant for the Basel_0.6 treatment (Belief difference for the low tax rate*Belief_0.6), whereas under the high tax scheme this coefficients are significant for both Belief treatments.

Result 3. Those low-skilled workers who believe that they are more productive than the other low-skilled workers in their group vote more frequently for the low tax rate. This is enhanced in the scenario with a high polarization of policy platforms.

\subsection{Evolution of voting behavior}

Let us now examine the evolution of the voting behavior in time. First, we will focus on the 0.4 high tax rate scenario. Figure 4 displays the average percentage of votes for the low tax rate $(\mathrm{t}=$ 0.2) by the Poor agents in each of the 9 periods. We can observe that in the Baseline, the percentage of votes is pretty stable between $30 \%$ and $40 \%$. However, in the Info, despite the starting point being very similar to that of the Baseline (40\%), there is a dramatic drop to $15 \%$ in the second period. This seems to be a huge effect of the information they received in the first period about their payoffs. The percentage of votes for the low tax rate keeps falling gradually 
down to $5 \%$. Thus, previous results of highly significant differences between those treatments are also sustained over time. Note however that the evolution of the Belief treatment is somehow erratic with some ups and downs; this may be due to the effect of the information not being so clear and transparent as in the Info treatment.

Figure 4. Evolution in time of the average percentage of votes for $t=0.2$ by the Poor in the 0.4 high tax rate scenario.

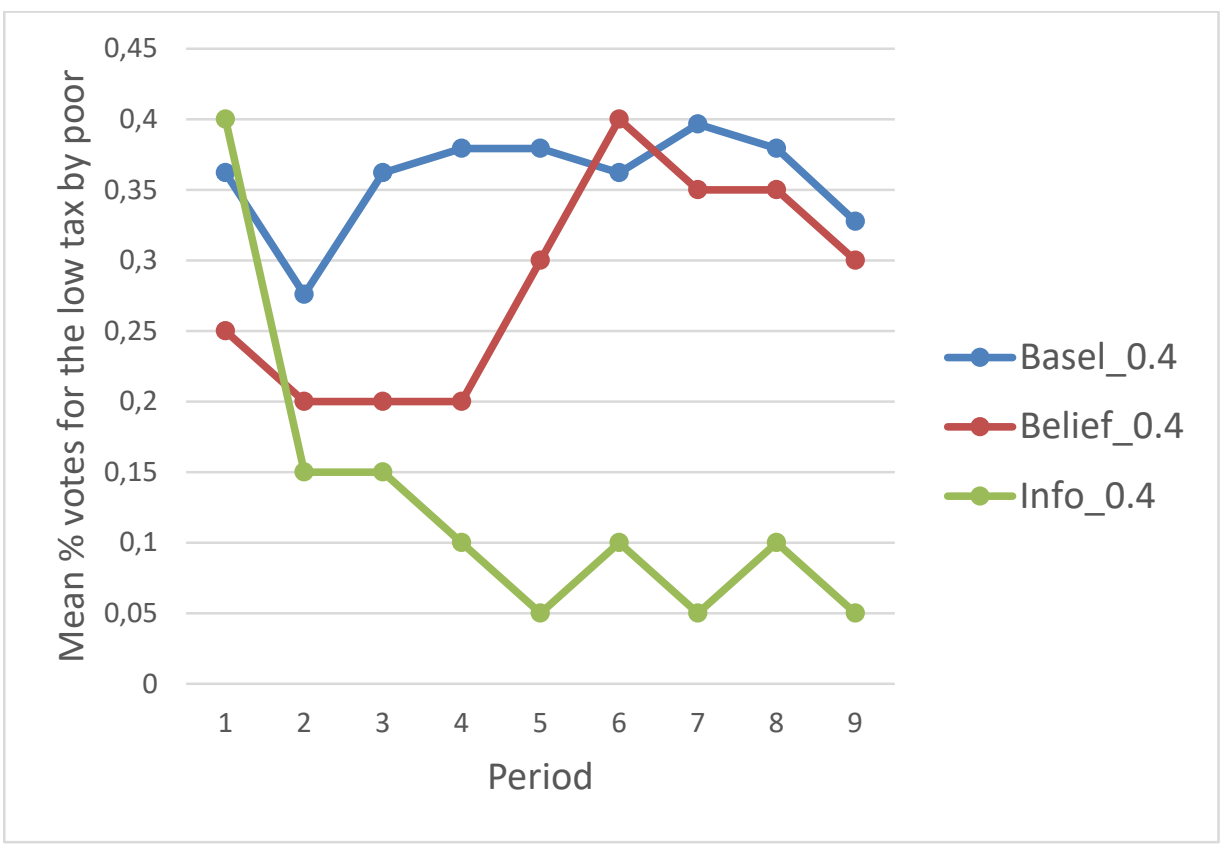

When the high tax rate is 0.6 (see Figure 5), the evolution in time is very similar to the previous one except that the percentage is around $10 \%$ higher on average. This is in line with Corollary 1, which states that a higher polarization increases the likelihood that the low tax rate will be implemented. It is interesting that in the Belief treatment the poor's voting behavior has a quite different evolution than before (0.4 scenario), since now there is a slightly decreasing trend and it is more similar to the Info treatment. This can be explained due to the fact that the opportunity cost of voting for the low tax rate for the poor increases with respect to the scenario in which the high tax rate is 0.4 . They may learn through the rounds that this effect overcomes the disincentive effect of high taxes on productivity. Again, differences between Baseline and Info hold over time. 
Figure 5. Evolution in time of the average percentage of votes for $\mathrm{t}=0.2$ by the Poor in the 0.6 high tax rate scenario.

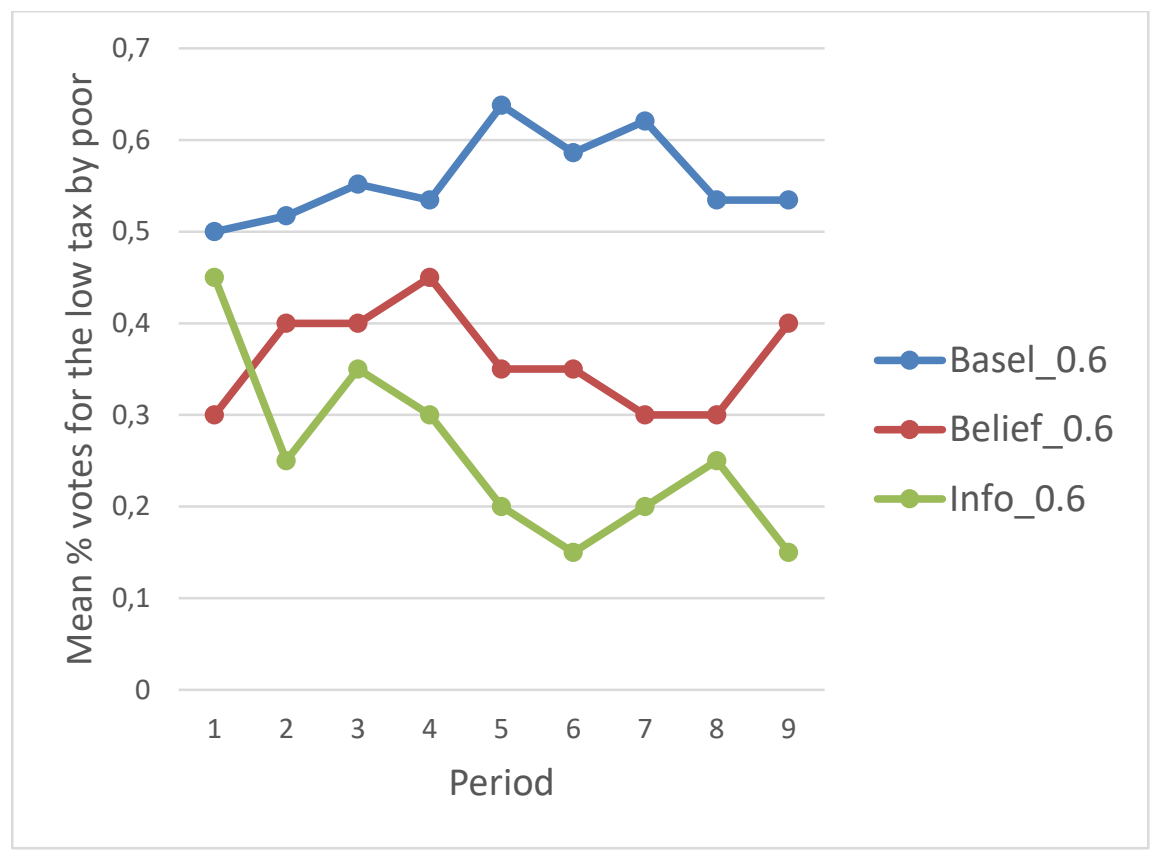

\subsection{Performance in the task}

The focus in this analysis will be on the disincentive of the tax rate schemes. Therefore, we will compare the number of correct tables that subjects solve in each period when the tax rate implemented is the low rate with the case where the winner tax rate is the high rate. ${ }^{30}$ This variable is reported in Table 8 and it is split by the tax rate implemented. First, we analyze Rich performance. In Basel_0.4, the Rich's productivity is higher under the low tax rate $(p=0.042)$, while in Belief_0.4 ( $p=0.144$, weakly significant) the opposite happens. In all the remaining treatments, the differences in productivity are not statistically significant (minimum $p=0.482$ ). Turning our attention to the Poor, again, in Basel_0.4 they work more under the low tax rate ( $p=$ 0.191, weakly significant) and they work less in Beliefs_0.6 $(p=0.033)$ and Info_0.6 $(p=$ 0.017). One possible explanation is that when the tax rate implemented is quite high (0.6), the Poor feel that they should work more (and reciprocate) since they are taking away a big

\footnotetext{
${ }^{30}$ This variable is indeed productivity. To study pure effort levels, we need to compute the total number of tables (correct and incorrect) solved. As one may expect, the number of total tables and only those correct are highly correlated (89\%, minimum for the four treatments). Thus, it does not seem very sensible to analyze both of them.
} 
proportion of the Rich's production. In all the remaining treatments, the differences in productivity are not statistically significant (minimum $p=0.209$ ).

We also explore this issue when we pool together all observations from all six treatments. Overall, the Rich did not decrease their productivity when the tax rate is increased ( $p=0.471)$. This is in line with Saez et al. (2012), who find no "convincing evidence in the short or medium run of large real economic activity responses of upper earners to tax rates”. Nevertheless, we observe that the Poor increase their productivity when the tax rate implemented increases $(p=$ 0.027), which (although not explained by our theoretical model) might be explained by social preferences such as guilt or reciprocity (especially in our setting when there is meritocracy in earning the right to belong to the Rich group).

Table 8: Descriptive statistics of agents' decisions on productivity and earnings

\begin{tabular}{|c|c|c|c|c|c|c|c|}
\hline & & \multicolumn{3}{|c|}{ High Tax Rate $=0.4$} & \multicolumn{3}{|c|}{ High Tax Rate $=0.6$} \\
\hline \multicolumn{2}{|c|}{ Agents } & All & Rich & Poor & All & Rich & Poor \\
\hline \multirow{3}{*}{$\begin{array}{l}\text { Correct under } \\
\mathrm{t}=0.2\end{array}$} & Basel & 8.9 & 10.6 & 8.0 & 7.8 & 10.7 & 6.4 \\
\hline & Belief & 7.3 & 8.1 & 6.9 & 6.5 & 7.2 & 6.1 \\
\hline & Info & 6 & 6.6 & 5.8 & 7.1 & 9.3 & 6 \\
\hline \multirow{3}{*}{$\begin{array}{l}\text { Correct under } \\
\mathrm{t}=0.4 \text { or } \mathrm{t}=0.6\end{array}$} & Basel & 8.6 & 11.6 & 7.2 & 8.4 & 10.7 & 7.3 \\
\hline & Belief & 7.8 & 8.9 & 7.2 & 7.6 & 7.6 & 7.6 \\
\hline & Info & 7.6 & 9.5 & 6.7 & 8.5 & 10.9 & 7.3 \\
\hline \multirow{3}{*}{$\begin{array}{l}\text { Total Payoffs } \\
\text { in all periods } \\
\text { per capita }\end{array}$} & Basel & \multicolumn{3}{|c|}{9663} & \multicolumn{3}{|c|}{8978} \\
\hline & Belief & \multicolumn{3}{|c|}{7975} & \multicolumn{3}{|c|}{7218} \\
\hline & Info & \multicolumn{3}{|c|}{7890} & \multicolumn{3}{|c|}{8849} \\
\hline \multirow{3}{*}{$\begin{array}{l}\text { Payoffs after } \\
\text { redistribution }\end{array}$} & Basel & 1074 & 1768 & $726(23 \%)$ & 998 & 1694 & $650(22 \%)$ \\
\hline & Belief & 886 & 1376 & $641(24 \%)$ & 802 & 1154 & $626(26 \%)$ \\
\hline & Info & 877 & 1367 & 632(24\%) & 983 & 1501 & $724(25 \%)$ \\
\hline \multicolumn{2}{|l|}{$\mathrm{N}$} & 144 & 48 & 96 & 144 & 48 & 96 \\
\hline \multicolumn{8}{|c|}{$\begin{array}{l}\text { Note: Rich[Poor] refers to those subjects receiving the high[low] wage. Correct is the average number of correct tables solved } \\
\text { by subjects in the } 9 \text { periods. Payoffs after redistribution are average individual payoffs after the tax collected was redistributed } \\
\text { within groups. Total payoffs in all periods per capita are the total sum of the payoffs in all } 9 \text { periods divided by the total } \\
\text { number of subjects in the corresponding treatment. All variables are displayed on average terms except Total payoffs in all } \\
\text { periods per capita. }\end{array}$} \\
\hline
\end{tabular}




\subsection{Efficiency and Income Inequality}

We consider the sum of all payoffs within groups in each period as the measure of efficiency. Interestingly, if we consider the sum of total payoffs in all 9 periods per capita, the Baseline entails an efficiency enhancement under the 0.4 high tax rate (9663 vs. 7975, 17\%, and 9663 vs. 7890, 18\%, for the Baseline vs the Belief and the Info, respectively). In fact, we find that the differences in average total payoffs are statistically significant. ${ }^{31}$ Thus, it seems that information damages efficiency when policy platforms are not very polarized. This is because more informed low-income voters make it more likely for the high tax rate to be implemented. However, when the high tax rate is 0.6, efficiency is only reduced in the Belief treatment by around $19 \%$ with respect to the other two treatments. ${ }^{32}$

Regarding equality, one way of measuring post-tax income inequality is calculating low-skilled agents' payoffs after tax redistribution as a percentage of the total payoffs in their group (in Table 8, see percentages in parentheses in the Poor column and the variable Payoffs after redistribution). Wealth share is very similar for the two different high tax rates in the Belief and the Info treatments. It is a bit lower in the Baseline treatment, presumably due to the low frequency of implementation of the high tax rate. Nevertheless, differences are not statistically significant (minimum $p=0.282$, two-tailed) except for the high tax rate 0.6 , where the wealth share in the Baseline is lower than in the other two treatments. ${ }^{33}$

Another standard measure used in the economics literature to determine income inequality is the Gini Index. ${ }^{34}$ The results are very similar to the previous ones. The Gini index is higher in the Baseline than in the other two treatments for both high tax rates $(0.31,0.26,0.26$ and $0.33,0.21$ and 0.25, for Basel_0.4, Belief_0.4, Info_0.4 and Basel_0.6, Belief_0.6, Info_0.6, respectively). Again, the more likely explanation is the higher frequency of votes for the low tax rate in the Baseline treatments.

\footnotetext{
${ }^{31} p=0.027$ and $p=0.025$ for Basel_0.4 vs Belief_0.4 and Basel_0.4 vs Info_0.4, respectively.

${ }^{32} p=0.002$ and $p=0.035$ for Basel_0.6 vs Belief_0.6 and Info_0.6 vs Belief_0.6, respectively.

${ }^{33} p=0.002$ and $p=0.035$ for Basel_0.6 vs Belief_0.6 and Basel_0.6 vs Info_0.6, respectively.

${ }^{34}$ The Gini coefficient proposed by the statistician Corrado Gini is a number between 0 and 1 , where 0 corresponds to perfect equality (all have the same income) and where the value 1 corresponds to perfect inequality (one person has all the income and the other none).
} 
Result 4. If the policy platforms are not very polarized, Information about how the tax rate operates in redistributing income lowers efficiency but also income inequality.

\section{Concluding Remarks}

According to the Eurobarometer ${ }^{35}, 84 \%$ of Europeans think that income differences are too great, and more than $60 \%$ consider that governments should take measures to reduce those differences. ${ }^{36}$ Despite this concern, income inequality is increasing in most countries. This article complements the existent literature trying to solve this puzzle. In particular we are interested in explaining the support from low-income voters of tax policies that increases income inequality. To this end, we test a model based on the Meltzer and Richard (1981) framework through a lab experiment in which individuals vote over two exogenous tax rates and their pre-tax income is determined according to their performance in a real-effort task with leisure. We show that a large proportion of low-income workers vote for the low tax rate even though that is the rate that minimizes their payoffs.

We propose two treatments to try to explain this counter-intuitive voting behavior. First, following Bartels (2005) and Kuziemko et al. (2015), we exploit the role of the lack of connection between tax rates and income redistribution. In particular, we provide information about the payoffs subjects would have earned if the alternative tax rate had been implemented (all other things being equal). We show that, once the low-income voters learn that the high tax rate benefits them more than the low rate, a large proportion of those voters shift their votes towards the high tax rate. However, around $10 \%$ of the votes cast by low-income voters remain for the low tax rate.

\footnotetext{
35 The Eurobarometer is a series of surveys carried out periodically by the European Commission since 1973. Its main function is to analyze and summarize public opinion on certain issues related to the European Union around the member states, thus being one of the more relevant instruments for analyzing the evolution of citizen opinion. See https://es.wikipedia.org/wiki/Eurobar\%C3\%B3metro.

${ }^{36}$ See the report "Special Eurobarometer, How fair do Europeans think life in the EU is?" published in Brussels, on 23th April 2018.
} 
Second, we study the impact of low-income voters' beliefs about their own and others' productivity on voting behavior. A possible motivation for the poor to vote for the low tax rate is the belief that a high tax rate may reduce productivity and so income redistribution. We only find support for this motivation when the high tax rate is very high.

We are aware that our study is not free of caveats. Although we include the possibility of leisure in our experimental design, the time spent on leisure is rather small and this may underestimate the effect of tax rate on productivity. A possible solution may be to pay for the leisure time spent, as per Sausgruber et al. (2019). However, in line with our results, empirical evidence supports the limited effect of taxes on top earners’ productivity.

Another reason that can explain this voting behavior is that the poor may overestimate their own productivity. This is related with the theory or prospect of upward mobility in Benabou and Ok (2001). In line with this theory, our results in the experiment confirm that those lowincome voters who overestimate their productivity are more likely to vote for the low tax rate.

Finally, the policy implications of our findings indicate that we should expect that parties against a high welfare state would try to make the connection between taxes and income redistribution weaker, while parties in favor would emphasize it. Moreover, less redistributive parties would stress the prospect of social mobility and beliefs that taxation reduces economic activity (even if neither were real).

\section{References}

Ackert, L. F., Martinez-Vazquez, J., Rider, M. (2007). “Social Preferences and Tax Policy Design: Some Experimental Evidence.” Economic Inquiry 45(3), 487-501.

Agranov, M., Palfrey, T. R. (2015). “Equilibrium Tax Rates and Income Redistribution: A laboratory Study.” Journal of Public Economics 130, 45-58.

Agranov, M., Palfrey, T. R. (2016). “The Effects of Income Mobility and Tax Persistence on Income Redistribution and Inequality.” NBER Working Paper No. 22759.

Alesina A., Angeletos G.M. (2005). "Fairness and Redistribution.” The American Economic Review 95(4), 960-980.

Alvaredo, F., Chancel, L., Piketty, T., Saez, E., Zucman, G., (2018). World Inequality Report 2018. Paris: World Inequality Lab. 
Alvaredo, F., Atkinson, A., Piketty T., Saez, E.(2011). The World Top Incomes Database. http://topincomes.g-mond.parisschoolofeconomics.eu/ (accessed November2012).

Atkinson, A., Piketty T., Saez, E..(2011). “Top Incomes in the Long Run of History.” Journal of Economic Literature 49 (1): 3-71.

Bartels, L. (2005). Homer Gets a Tax Cut: Inequality and Public Policy in the American Mind. Perspectives on Politics,3(1), 15-31.

Bénabou, R, Ok. E. A. (2001). "Social Mobility and the Demand for Redistribution: The POUM Hypothesis.” Quarterly Journal of Economics 116 (2): 447-87

Bolton, G. E., Ockenfels, A. (2006). “Inequality Aversion, Efficiency, and Maximin Preferences in Simple Redistribution Experiments: Comment.” The American Economic review 96(5), 1906-1911.

Cabrales, A., Nagel R. and Rodríguez Mora, J.V. (2012), "It is Hobbes, not Rousseau: an experiment on voting and redistribution”, Experimental economics, 15(2): 278-308.

Charité, J., Fisman, R., and Kuziemko, I. (2015). “Reference Points and Redistributive Preferences: Experimental Evidence.” National Bureau of Economic Research, No. w21009.

Corgnet, B., Hernán-González, R., and Schniter, E. (2015). "Why Real Leisure Really Matters: Incentive Effects on Real Effort in the Laboratory.” Experimental Economics 18(2), 284-301.

Deaton, A (2013),The Great Escape: Health, Wealth, and the Origins of Inequality, Princeton University Press

Durante, R., Putterman, L., and Weele, J. (2014). "Preferences for Redistribution and Perception of Fairness: An Experimental Study.” Journal of the European Economic Association 12(4), 1059-1086.

Fehr, E., and Schmidt, K. M. (1999).“A Theory of Fairness, Competition, and Cooperation.” Quarterly journal of Economics, 817-868.

Fischbacher, U. (2007), “Z-Tree: Zurich Toolbox for Ready-made Economic Experiments,” Experimental Economics, 10(2): 171-178.

Fisman, R., Kariv, S., and Markovits, D. (2007).“Individual Preferences for Giving.” The American Economic Review 97(5), 1858-1876.

Fong, C. M. (2001). "Social Preferences, Self-Interest, and the Demand for Redistribution.” Journal of Public Economics 82 (2): 225-46.

Gimpelson, V, Treisman, D. (2018) “Misperceiving inequality.” Econ Polit. 2018; 30: 27_ 54. 
Goldin, C., and Katz, L (2008),The Race Between Education and Technology, Harvard University Press

Holmstrom, B. (1982). “Moral hazard in teams.” The Bell Journal of Economics, 324-340.

Krawczyk, M. W. (2011). “A Model of Procedural and Distributive Fairness.” Theory and decision 70(1), 111-128.

Kuziemko, I., Buell, R. W., Reich, T., Norton M. I. (2014) “Last-Place Aversion: Evidence and Redistributive Implications.” The Quarterly Journal of Economics 129 (1): 105-149.

Kuziemko, I., Norton, M. I., Saez, E., Stantcheva, S. (2015) How Elastic Are Preferences for Redistribution? Evidence from Randomized Survey Experiments American Economic Review, 105(4): 1478-1508

Meltzer A. H. and Richard S. F. (1981).“A Rational Theory of the Size of Government.” Journal of Political Economy 89, 914-927.

Piketty, T.(1998). “Self-fulfilling beliefs about social status. ” Journal of Public Economics 70, 115-132.

Piketty, T.(2014). Capital in the Twenty-First Century. Cambridge, MA: Harvard University Press.

Piketty, T., Saez, E. (2003). “Income Inequality in the United States, 1913-1998.” Quarterly Journal of Economics 118 (1): 1-39.

Roberts K. W. (1977). “Voting over Income Tax Schedules.” Journal of Public Economics 8, 329-340.

Romer T. (1975).“Individual Welfare, Majority Voting, and the Properties of a Linear Income Tax.” Journal of Public Economics 4, 163-185.

Roemer, J. E. (1998). Why the poor do not expropriate the rich: An old argument in new garb. Journal of Public Economics, 70 (3): 399-424.

Saez, E., Slemrod, J., Giertz, S.H. (2012) “The Elasticity of Taxable Income with Respect to Marginal Tax Rates: A Critical Review.” Journal of Economic Literature 50 (1): 3-50.

Sausgruber, R., Sonntag, A., Tyran, J. R. (2019) “Disincentives from redistribution: evidence on a dividend of democracy.” Discussion Paper DP13773. Centre for Economic Policy Research.

Tyran, J. R., and Sausgruber, R. (2006). “A little fairness may induce a lot of redistribution in democracy.” European Economic Review 50(2), 469-485.

Wanniski, J. (1978). “Taxes, Revenues and the "Laffer Curve”, The Public Interest, 50: 3-14. 


\section{Appendix A. Proofs.}

\section{Proof of Proposition 1.}

The optimal tax rate for skilled and unskilled workers is given by the solution of the following maximization problem:

$$
\begin{aligned}
\max _{t} u\left(x_{i}^{*}, t\right) \\
\text { s.t. } t \in[0,1]
\end{aligned}
$$

Recall that we assume that $\beta$ is low enough such that $x_{i}^{*}>0$. However there is a real posibillity of the opposite corner solution (with a very low $\beta$ ) in which both types of workers prefer to spend the whole time working, i.e. $x_{i}^{*}=1$. It is straightforward that in this case the optimal tax rate for each type is, respectively, $t_{s}^{*}=0$ and $t_{u}^{*}=1$.

Considering now the interior solutions for the labor supply (that is the case of $\beta$ high enough such that $x_{i}^{*} \in(0,1)$ ), the first order conditions (FOC) of the maximization problem are for unskilled and skilled workers respectively:

$$
\begin{aligned}
& \frac{1}{n}\left(w_{u}^{2} n_{s}-2 w_{s}^{2} n_{u}\right) t_{u}^{*}+\left(w_{s}-w_{u}\right)\left(w_{s}+w_{u}-\beta\right)=0 \\
& \frac{1}{n}\left(w_{s}^{2} n_{u}-2 w_{u}^{2} n_{s}\right) t_{s}^{*}+\left(w_{u}-w_{s}\right)\left(w_{s}+w_{u}-\beta\right)=0
\end{aligned}
$$

From the first order condition we obtain that the optimal tax rate for the unskilled workers is:

$$
t_{u}^{*}=\frac{n\left[\left(w_{s}-w_{u}\right)\left(w_{s}+w_{u}-\beta\right)\right]}{2 n_{u} w_{s}^{2}-n_{s} w_{u}^{2}}
$$

Let us now check whether $t_{u}^{*} \in[0,1]$. First, we prove that $t_{u}^{*}>0$. From the FOC we can check it:

$$
\begin{gathered}
\left(w_{s}-w_{u}\right)\left(w_{s}+w_{u}-\beta\right)>0 \text {, and } \\
w_{u}^{2} n_{s}-2 w_{s}^{2} n_{u}<0
\end{gathered}
$$

Second, we prove that $t_{u}^{*}<1$. From the FOC $t_{u}^{*}>0$, if and only if:

$$
\begin{aligned}
& n\left(w_{s}-w_{u}\right)\left(w_{s}+w_{u}-\beta\right)<2 w_{s}^{2} n_{u}-w_{u}^{2} n_{s} \Leftrightarrow \\
& n\left(\left(w_{s}^{2}-w_{u}^{2}\right)-\beta\left(w_{s}-w_{u}\right)\right)<2 w_{s}^{2} n_{u}-w_{u}^{2} n_{s}
\end{aligned}
$$


But this is always true since $2 n_{u} w_{s}^{2}-n_{s} w_{u}^{2}>n\left(w_{s}^{2}-w_{u}^{2}\right)$. Notice also that the second order condition for unskilled workers is satisfied since $w_{u}^{2} n_{s}-2 w_{s}^{2} n_{u}<0$.

Let us now analyze the optimal tax rate for skilled workers. From the FOC, we obtain that $t_{s}^{*}=0$ if $w_{s}^{2} n_{u}-2 w_{u}^{2} n_{s} \leq 0$, otherwise (if $w_{s} / w_{u}>\sqrt{2\left(n_{s} / n_{u}\right)}$ ) the optimal tax rate is either $t_{s}^{*}=0$ or $t_{s}^{*}=1$. Comparing the utility level for both $t_{s}^{*}=0$ and $t_{s}^{*}=1$ we have the following:

$$
\begin{gathered}
u\left(x_{s}^{*}, 0\right)>u\left(x_{s}^{*}, 1\right) \Leftrightarrow \\
\frac{\left(w_{s}-\beta\right)^{2}}{2}>\frac{\left(\frac{n_{s}}{n} w_{s}-\beta\right)^{2}}{2}+\frac{n_{u} w_{u}}{n}\left(\frac{n_{u} w_{u}}{n}-\beta\right) \Leftrightarrow \\
\beta<\frac{w_{s}^{2}\left(n+n_{s}\right)-2 n_{u} w_{u}^{2}}{n\left(w_{s}-2 w_{u}\right)} \Leftrightarrow \\
\beta<w_{u}\left(\frac{p^{2}\left(n+n_{s}\right)-2 n_{u}}{n(p-2)}\right)
\end{gathered}
$$

where $p=\frac{w_{s}}{w_{u}}$. Since we know that $\beta<w_{u}$, the above inquality is always satisfied if:

$$
\begin{gathered}
\frac{p^{2}\left(n+n_{s}\right)-2 n_{u}}{n(p-2)} \geq 1 \Leftrightarrow \\
p^{2}\left(n+n_{s}\right)-n p+2 n_{s} \geq 0
\end{gathered}
$$

and this is always true because $p>1$. Therefore the optimal tax rate for skilled workers is $t_{s}^{*}=0$.

\section{Proof of Proposition 2.}

From Proposition 1 we know that the optimal tax rate for unskilled workers is given by the following equation:

$$
t_{u}^{*}=\frac{n\left[\left(w_{s}-w_{u}\right)\left(w_{s}+w_{u}-\beta\right)\right]}{2 n_{u} w_{s}^{2}-n_{s} w_{u}^{2}}=\frac{n\left[w_{s}^{2}-w_{u}^{2}-\beta\left(w_{s}-w_{u}\right)\right]}{2 n_{u} w_{s}^{2}-n_{s} w_{u}^{2}}
$$

From this expression it is straightfoward to prove that $\frac{d t_{u}^{*}}{d \beta}<0$.

To prove the second statement of the proposition we divide the numerator and denominator of the previous expression by $w_{u}^{2}$ and we take $p=\frac{w_{s}}{w_{u}}$. By doing so we rewrite it as:

$$
t_{u}^{*}=\frac{n\left[p^{2}-1-\frac{\beta}{w_{u}}(p-1)\right]}{2 n_{u} p^{2}-n_{s}}
$$


We calculate the derivative $\frac{d t_{u}^{*}}{d p}$ to check its sign:

$$
\begin{gathered}
\frac{d t_{u}^{*}}{d p}=\mathrm{n} \cdot \frac{\left[2 p-\frac{\beta}{w_{u}}\right]\left(2 n_{u} p^{2}-n_{s}\right)-4 n_{u} p\left[p^{2}-1-\frac{\beta}{w_{u}}(p-1)\right]}{\left(2 n_{u} p^{2}-n_{s}\right)^{2}}= \\
=n \cdot \frac{p\left(4 n_{u}-2 n_{s}-n_{u} \frac{\beta}{w_{u}}(4-2 p)\right)+\frac{\beta}{w_{u}} n_{s}}{\left(2 n_{u} p^{2}-n_{s}\right)^{2}}>0
\end{gathered}
$$

The inequality above is always satisfied because $\frac{\beta}{w_{u}}<1$, which implies that:

$$
\begin{gathered}
4 n_{u}-2 n_{s}-n_{u} \frac{\beta}{w_{u}}(4-2 p)= \\
2\left(n_{u}-n_{s}\right)+n_{u}\left(2-2 \frac{\beta}{w_{u}}(2-p)\right)>0 .
\end{gathered}
$$

\section{Proof of Proposition 3.}

Introducing (2) in (1) we obtain the following indirect utility function $v(t)=A t^{2}+B t+C$ where

$$
\begin{gathered}
A=\frac{n_{s}}{2 n^{2}}\left(n_{s} w_{u}^{2}-2 n_{u} w_{s}^{2}\right) \\
B=\frac{n_{s}\left(w_{s}-w_{u}\right)}{n}\left(w_{s}+w_{u}-\beta\right)
\end{gathered}
$$

An unskilled worker prefers to vote for $t^{l}$ rather than for $t^{h}$ if and only if $v\left(t^{l}\right) \geq v\left(t^{h}\right)$; that is,

when:

$$
\begin{gathered}
A\left(t^{l}\right)^{2}+B t^{l} \geq A\left(t^{h}\right)^{2}+B t^{h} \Leftrightarrow \\
\left(A\left(t^{l}+t^{h}\right)+B\right)\left(t^{l}-t^{h}\right) \geq 0
\end{gathered}
$$

Since $t^{l}-t^{h}<0$, this implies that $v\left(t^{l}\right) \geq v\left(t^{h}\right)$ if and only if $A\left(t^{l}+t^{h}\right)+B \leq 0$. Notice that $A<0$ because $w_{s}>w_{u}$ and $n_{s}<n_{u}$. Moreover, notice that $B>0$ because $\beta<w_{s}+w_{u}$. Substituting $A$ and $B$ we find that an unskilled worker prefers to vote for $t^{l}$, if and only if:

$$
\frac{t^{l}+t^{h}}{2} \geq \frac{n\left[\left(w_{s}-w_{u}\right)\left(w_{s}+w_{u}-\beta\right)\right]}{2 n_{u} w_{s}^{2}-n_{s} w_{u}^{2}}=t_{u}^{*}
$$




\section{Appendix B. Instructions for the Baseline or the Information Treatments ${ }^{37}$}

\section{INSTRUCTIONS}

The aim of this experiment is to study how individuals make decisions in certain environments. The instructions are simple and if you follow them carefully, you will get a monetary payoff at the end of the experiment. This payoff will be confidential, since nobody will know the payoffs received by the other participants. You can ask all the questions you have by raising your hand at any moment. Apart from these questions, any kind of communication between you is forbidden and it will mean an immediate expulsion from the Experiment.

This experiment has two phases:

\section{Phase 1}

In the first phase, you will have to do a task based on additions that lasts 4 minutes (240 seconds). The task will consist of adding up 16 numbers in a table of 4 rows and 4 columns. The difficulty of the tables will be the same for all participants. Before writing in the screen a final solution (the summation of all the numbers in the table), you will have to complete the 4 cells that correspond to the addition of each row and the 4 cells that correspond to the addition of each column. You will be able to write the final solution of the table (red box in Figure 1) once you have completed the 8 previous cells.

The use of a calculator or any other electronic device is forbidden. If you use any such device, you will be expelled from the experiment with no payoffs.

You can see an example of what will be shown on the screen in Figure 1:

Figure 1

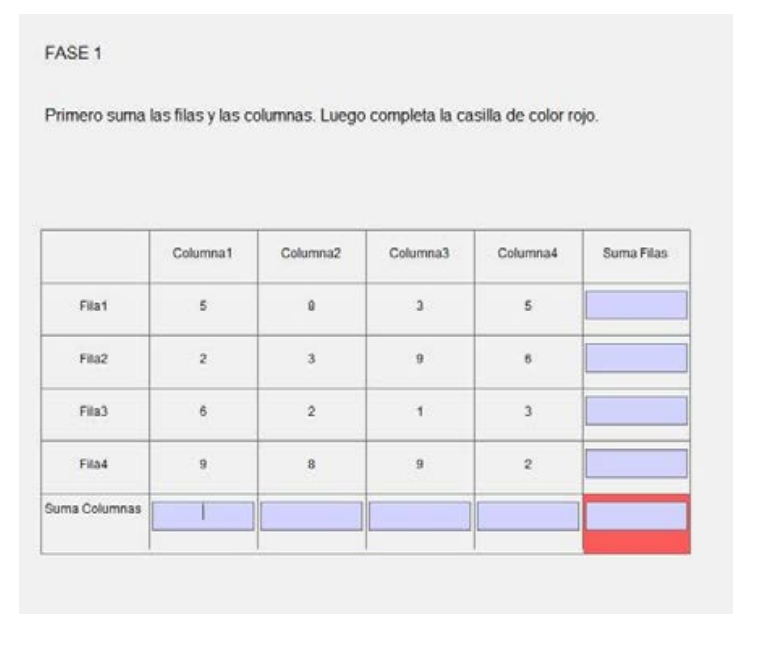

${ }^{37}$ Instructions for other treatments are available upon request. 
At the end of the $\mathbf{4}$ minutes, the number of tables that have been correctly summed will be calculated for all the participants in the current session. The number of correct tables will only depend on the solution written in the red box (the remaining cells will help you to calculate the final solution but they will not be taken into account). The top third of participants with the best results will belong to Group A, while the remaining two thirds of participants will belong to Group B. The members of Group A will receive 188 ECUS (experimental currency unit) for each correct table in the second phase of the experiment, while the members of Group B will receive 75 ECUS (experimental currency unit) for each correct table in the second phase of the experiment. In the event of a tie in the number of correct summations, the tied participants will do the same task for $\mathbf{1}$ minute and a half. If this results in a tie again, the tie-breaking will be randomly decided between the tied participants.

\section{Phase 2}

In this phase, you will be matched with two other people participating in the session to form a group of three. In this way, there will be one participant of Group A and two participants of Group B in each group.

You must know that in all rounds of Phase 2 your group will be always the same. This means that you will be matched with the same people throughout all the rounds.

Phase 2 consists of several rounds with a length of 8 minutes each. During this time you can do the task of summations (identical to the task of Phase 1) or surf the Internet. To change from one task to the other you need to push the button SURF (in the upper right part of the screen, Figure 2).

A certain amount of the ECUS earned by the members of your group during the task will be redistributed between the members of the group through a tax rate. Figure 2 shows an example of the screen in Phase 2.

Phase 2 is formed by two blocks of rounds. In the first block the tax rate will be set (you cannot choose it) and these rounds will be trial rounds, so they will not be taken into account to calculate payoffs. In the second block the tax rate will be chosen by voting in all rounds.

In summary, Phase 2 consists of:

\section{Block 1 (set tax rate, trial rounds)}

At the beginning of each round, a tax rate will be announced. This tax rate will be the one applied to the ECUS you will obtain in that round according to the number of correct tables. Subsequently, the 8 minutes of the round to perform the task will start. The collected tax revenues in your group will be equally distributed among all the group members. The calculus of your payoff and how the tax will be implemented will be further explained in detail below. 
Figure 2

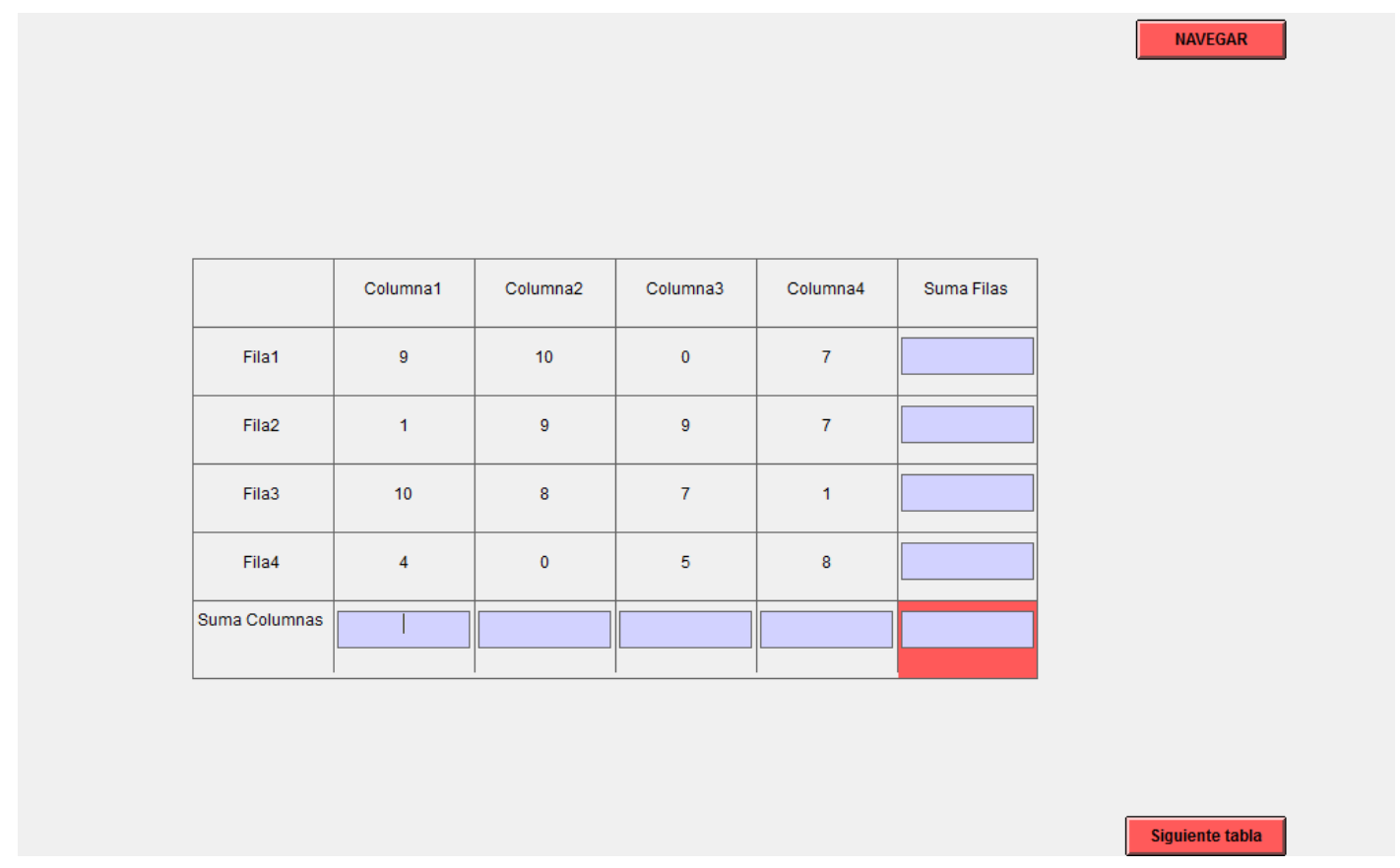

\section{Block 2 (tax chosen by voting)}

At the beginning of each round, two different tax rates are presented. You will have to choose one of them. The tax rate that receives more votes in the group will be applied in that round. Notice that since the groups are formed by 3 people there is no option of a tie in the voting procedure. As in the rounds with a fixed tax rate, the tax rate elected by majority rule will be announced before starting the 8 minutes of the round.

\section{Your payoff in each round}

For calculating your payoff in a round, we need several steps. Your payoff before taxes will be calculated multiplying the number of correct tables obtained in that round by $\mathbf{1 8 8}$ if your type is A or by $\mathbf{7 5}$ if your type is B. Secondly, for calculating your payoff after taxes, your payoff before taxes will be multiplied by (1-t), where $t$ is the tax rate announced in rounds with the tax rate set or that selected by majority rule in rounds with voting. Finally, the collected taxes ( $\mathrm{t}^{*}$ addition of payoffs before taxes) in your group are divided equally between all the members of your group (that is, divided by 3 ) will be added to your payoff. The payoff of a round can be calculated as follows:

$\left.\operatorname{payoff}_{(\text {type } B}\right)=(1-t) \times \operatorname{correct}_{B} \times 75+t \times\left(\frac{\text { correct }_{B 1} \times 75+\operatorname{correct}_{B 2} \times 75+\operatorname{correct}_{A} \times 188}{3}\right)$ 
where $t$ is the tax rate, correct $t_{j}$ is the number of correct tables obtained in that round, depending on your type $\mathrm{j}=\mathrm{A}, \mathrm{B}$.

\section{$\underline{\text { Example } 1}$}

Suppose that your type is $\mathbf{A}$ and the announced tax rate in that round is $30 \%$, that is $t=0.3$. If you have solved 6 correct tables during the 8 minutes of the round ( correct $_{A}=6$ ), another member has solved $5\left(\right.$ correct $\left._{B 1}=5\right)$ and the other member 4 ( correct $\left._{B 2}=4\right)$, then, your payoffs will be:

\section{Before taxes:}

correct $_{A} * 113=6 * 113=\mathbf{6 7 8}$ ECUS

\section{After taxes (including distribution of collected tax revenues):}

$\left[(1-t) * \operatorname{correct}_{A} * 113\right]+\left[(\mathrm{t} / 3) *\left(\operatorname{correct}_{\mathrm{B} 1} * 75+\operatorname{correct}_{\mathrm{B} 2} * 75+\operatorname{correct}_{A} * 188\right)\right]=$

$=[(1-0.3) * 6 * 113]+[(0.3 / 3) *(5 * 75+4 * 75+6 * 188)]=474.6+179.1=653.7$ ECUS

\section{$\underline{\text { Example 2 }}$}

Suppose that your type is $\mathbf{B}$ and the announced tax in that round is $30 \%$, that is $t=0.3$. If you have solved 4 correct tables during the 8 minutes of the round (correct $\left.{ }_{B 1}=4\right)$, the other member of type B has solved 5 ( correct $_{B 2}=5$ ) and the member of type A has solved 7 ( correct $_{A}=7$ ), then, your payoffs will be:

\section{Before taxes:}

correct $_{B 1} * 75=4 * 75=\mathbf{3 0 0}$ ECUS

\section{After taxes (including distribution of collected taxes):}

$\left[(1-t) * \operatorname{correct}_{\mathrm{B} 1} * 75\right]+\left[(\mathrm{t} / 3) *\left(\operatorname{correct}_{\mathrm{B} 1} * 75+\operatorname{correct}_{\mathrm{B} 2} * 75+\operatorname{correct}_{A} * 188\right)\right]=$

$=[(1-0.3) * 4 * 75]+[(0.3 / 3) *(4 * 75+5 * 75+7 * 188)]=210+150.1=360.1$ ECUS

At the end of each round, you will be informed about the decisions made by the members of your group. At the end of the experiment, we will pay you for your decisions of $\mathbf{2}$ rounds of Block 2 (rounds with voting). These rounds will be randomly chosen.

In order to pay you according to your decisions, we will exchange your earnings in ECUS into Euros using the exchange rate $\mathbf{8 8}$ ECUS $=\mathbf{1 €}$. Your earnings will be anonymously given at the end of the experiment. 
APPENDIX C. DESCRIPTIVES ON LEISURE TIME

\begin{tabular}{|l|l|c|c|c|c|c|c|}
\cline { 2 - 8 } \multicolumn{2}{c|}{} & \multicolumn{3}{c|}{ High Tax Rate = 0.4 } & \multicolumn{3}{c|}{ High Tax Rate $=\mathbf{0 . 6}$} \\
\hline \multicolumn{2}{|c|}{ Agents } & All & Rich & Poor & All & Rich & Poor \\
\hline \multirow{3}{*}{$\begin{array}{l}\text { Surf time for } \\
\text { tax t=0.2 }\end{array}$} & Belief & 1.3 & 2.6 & 0.7 & 2.6 & 0.5 & 3.6 \\
\cline { 2 - 9 } & Info & 0.8 & 0.4 & 1.0 & 0.7 & 0.9 & 0.5 \\
\hline \multirow{2}{*}{$\begin{array}{l}\text { Surf time for } \\
\text { tax } \mathrm{t}=0.4 \text { or } \\
\mathrm{t}=0.6\end{array}$} & Belief & 3.0 & 0 & 4.5 & 0.3 & 0.5 & 0.2 \\
\cline { 2 - 9 } & Info & 1.3 & 3.5 & 0.2 & 3.4 & 1.3 & 38.5 \\
\hline \multicolumn{2}{|c|}{$\mathrm{N}$} & 144 & 48 & 96 & 144 & 48 & 96 \\
\hline
\end{tabular}




\section{PREVIOUS WORKING PAPERS IN THE SERIES}

Preferences for efficiency, rather than preferences for morality, drive cooperation in the one-shot Stag-Hunt Game. Valerio Capraro, Ismael Rodriguez-Lara, and Maria J. Ruiz-Martos

Fluctuations in Global Macro Volatility.

Danilo Leiva-Leon and Lorenzo Ductor

Current Account and International Networks.

Daryna Grechyna

Socioeconomic Correlates of Political Polarization: Evidence from English Counties.

Daryna Grechyna

Nudging responses to marketing emails: Evidence from London Fireworks Campaign.

Alice Gimblett and Daryna Grechyna

Mandatory Spending, Political Polarization, and Macroeconomic Volatility.

Daryna Grechyna

Conformity and truthful voting under different voting rules.

Bernardo Moreno, Maria del Pino Ramos-Sosa, and Ismael Rodriguez-Lara

On how to allocate the fixed cost of transport networks.

Teresa Estan, Natividad Llorca, Ricardo Martinez, and Joaquin Sanchez-Soriano

Multilevel proficiency comparisons with an application to educational outcomes in PISA.

Ricardo Martinez and Antonio Villar

Population structure and the human development index.

Carmen Herrero, Ricardo Martinez, and Antonio Villar

From Financial to Managerial Capitalism. The slow adaptation of Spanish corporate elite Downloads.

Juan A. Rubio Mondejar, Josean Garrues Irurzun and Luis Chirosa 